\title{
GAS TURBINE RELIABILITY ESTIMATION TO REDUCE THE RISK OF FAILURE OCCURRENCE WITH A COMPARATIVE STUDY BETWEEN THE TWO-PARAMETER WEIBULL DISTRIBUTION AND A NEW MODIFIED WEIBULL DISTRIBUTION
}

\author{
Ahmed Zohair DJEDDI 1,2, Ahmed HAFAIFA ${ }^{1,2}$, Abdelhamid IRATNI ${ }^{3}$, Abdellah KOUZOU ${ }^{1,2}$ \\ ${ }^{1}$ Applied Automation and Industrial Diagnostics Laboratory, Faculty of Science and Technology, \\ University of Djelfa 17000 DZ, Algeria \\ ${ }^{2}$ Gas Turbine Joint Research Team, University of Djelfa, Djelfa 17000 DZ, Algeria \\ ${ }^{3}$ Faculty of Science and Technology, University of Bordj Bou Arreridj, 34030 DZ, Algeria \\ Emails: a_z_djeddi@univ-djelfa.dz, a.hafaifa@univ-djelfa.dz, iratni@univ-bba.dz, a.kouzou@ univ-djelfa.dz
}

\section{Abstract}

Responding to the needs of quality and robustness of analysis and management of degradation of equipment, to increase their life cycle and to expand these facilities to become more and more sophisticated and agronomic. This work proposes a contribution to increase the survival of a gas turbine, installed in a gascompression plant, with a comparative study between the two-parameter Weibull distribution. A new modified Weibull distribution was proposed also to reduce the risk of occurrence of failure in this rotating machine. A Statistical analysis and validation on the synthesis of turbine's reliability data and failures were considered, with a particular focus on the use of this data to increase the availability of this type of machine. So, developing a maintenance plan based on their reliability indices for scheduled inspections

Keywords: Failure analysis, malfunction analysis, availability, reliability estimation, failure occurrence, maintenance plan, gas turbine, two-parameter Weibull, modified Weibull.

\section{INTRODUCTION}

The operation of gas transport facilities is subject to numerous regulatory, technical and economic constraints. Some gas installations cannot stop functioning under penalty of generating enormous financial losses, but a defect or failure can also adversely affect the quality of their production. It is against this backdrop that the present work proposes to prevent untimely breakdowns, to reduce the maintenance downtime duration, and optimizing the operating time of each component by deciding to intervene just in time using a reliability and availability approach for gas turbines. And also, this work is materialized by the development of application research work on the right reliability tools, to optimize maintenance and to provide engineering with advice and support for improving the gas transport system.

In fact, modern gas compression and transport installations are becoming more and more complex and their monitoring is more sophisticated. At the same time, reliability, availability and operational safety have become very important and a real challenge for these installations. Recently, several works have been carried out in the industrial literature to develop diagnostic methods and robust reliability of this system. Xiao et al. in [42] have proposed an analysis for reliability measures with their evaluation for the prediction of the life of gas turbine blades. Nadji Hadroug et al. in [26] modeled the reliability of a gas turbine using an adaptive neuro-fuzzy inference system. Jingfeng Zhao et al. in [16] studied the reliability with their evaluation for an electrical multiple energy storage system, and Ahmed Zohair Djeddi et al. in [5] modeled the reliability of gas turbines based on an optimized failure function. As well as Dengji Zhou et al. in [10] proposed a strategy for diagnosing gas turbine failures with thermodynamic analysis limiting the interference of boundary conditions. Choayb Djeddi et al. in [9] realized a robust diagnostic system for the protection of a gas turbine against failures based on a neuro-fuzzy monitoring approach.

In addition, several other works have been developed in recent years in this field, for the design of robust diagnostic and supervision systems with implementation of monitoring and diagnostic algorithms with reliability approaches based on the various information available ; Adel Alblawi in [1] proposed an approach to diagnose turbine failures based on the development of thermodynamic models 
coupled with the concept of artificial neural networks. As well Ben Rahmoune Mohamed et al. in $[7,22]$ proposed a monitoring system of a gas turbine, for the fault tolerant control of this rotating machine, using advanced techniques of artificial neural networks. This with the aim of developing predictive models for the detection and isolation of faults affecting the gas turbine studied. Other applications of artificial neural networks techniques have been developed by Dengji Zhou et al. in [13] and Mingliang Bai et al. in [20] for several investigations in the detection of failures of gas turbines, in this sense Morteza Montazeri Gh et al. in [23-24] worked on the concept of fuzzy logic type 2, for the learning of the characteristic maps of the defects using a neural model with automatic growth applied to gas turbines. Also, Boulanouar Saadat et al. in [8] studied the estimation of uptime in gas turbines using a prognostic modeling approach guided by studied turbine operating data and Tomas Olsson et al. in [41] tested turbine operating data to predict long-term degradation.

Hence, the learning approach has been widely studied, for applications for the diagnosis of gas turbines, Pak Kin Wong et al. in [28] developed a method of fault diagnosis for gas turbine generator systems in real time with an extreme learning machine and Shi-sheng Zhong et al. in [38] realized a transfer learning with $\mathrm{CNN}$ for the development of a new approach to gas turbine failure diagnosis. Also, Yanyan Shen et al. in [45], have proposed a hybrid fault diagnosis strategy with machine learning for applications to aircraft gas turbines.

In addition, other work has focused on the evaluation of the fatigue reliability of this type of rotating machine, such as the work of Herman Shen M.H. in [15] and the work of Rongzhuo Sun et al. in [32] focused on the coupling of faults in diagnosis with the control of gas turbines, thus the work Sandy Rahme et al. in [34] focused on the development of adaptive observers in sliding mode for the fault diagnosis of a gas turbine and the work of Yu Zhi Chen et al. in [46] and Zengbu Liao et al. in [47] focused on performance improvement and impact analysis on gas turbines with modern diagnostic approaches.

However, the reliability of systems in industrial processes is the ability to withstand failures and loads experienced during its operation of a real-time process. In fact, maintaining industrial installations in good condition is an essential activity in the search for performance in terms of reliability, maintainability, availability, and safety in turbine systems [2-4, 6, 12, 14, 18-19, 25, 27, 31]. It is in this context that we propose in this work, to prevent untimely breakdowns, reduce the duration of downtime necessary for maintenance and optimize the operating time of each organ by deciding to intervene just in time. We adopt a reliability approach based on the two-parameter Weibull distribution with a comparative study by a new modified Weibull distribution for the different calculations of the reliability indices, to optimize the reliability of the gas turbine and maintenance system in these industrial facilities.

This is done with malfunctions analysis of the turbine systems with the selection of maintenance tasks, which leads to proposing justified elementary tasks to cover the significant failure modes and to develop the maintenance program for this machine. It has increased the operating intervals between scheduled shutdowns and minimized the failure risk of the investigated turbine.

\section{WEIBULL-BASED RELIABILITY DISTRIBUTION}

The variation and evolution of the failure rate of a device during its entire lifetime is characterized by a reliability distribution, corresponding to the probability of occurrence of these failures. Hence, the modeling of the reliability distributions is a crucial issue for the operational safety of industrial systems, to ensure an optimal compromise between the five zeros of optimal operation such as zero accidents, zero downtime, zero faults, zero maintenance, and zero emissions [2-4].

To achieve these objectives in terms of quality and availability, and a reliable operation with guaranteed operating safety at reasonable costs, the Weibull reliability distribution is proposed. First, a reliability analysis using the two-parameter Weibull distribution will be done, then this latter will be compared to a modified Weibull distribution, using real data from MS5002C gas turbine. The proposed reliability approach makes it possible to model the damage effects to predict the operating performance of the examined gas turbine. As well as providing comparable results in terms of validity against the Weibull two-parameter approach. This analysis then has the aim of increasing their reliability and using reliability indices to be able to carry out risk analyzes specific to this gas transport installation.

\subsection{Two-parameter Weibull distribution}

The Weibull-based reliability distribution, having parameters that make it possible to ensure a better representative of the phenomena of failure and degradation of the turbine studied. The Weibull distribution characterizes well the behavior of the product in the three phases of the life of a system, divided into three distinct periods; Period of infant mortality characterized by decreased failure rate, Normal period characterized by essentially constant failure rate and Aging period characterized by rapid increase in failure rate as a result of equipment degradation due to age or use, depending on the value of the shape parameter $\beta$, for the period of youth $\beta \prec 1$, period of useful life $\beta=1$ and for the period of wear or aging $\beta>1$. The two-parameter Weibull distribution is characterized by its survival function, given by $[3,30]$ :

$$
R(t)=e^{-\left(\frac{t}{\eta}\right)^{\beta}}
$$


with $\beta$ is the shape parameter and $\eta$ is the scale parameter.

And the probability density, given by $[4,35]$ :

$$
f(t)=\frac{\beta}{\eta}\left(\frac{t}{\eta}\right)^{\beta-1} e^{-\left(\frac{t}{\eta}\right)^{\beta}}
$$

With the failure rate, given by:

$$
\lambda(t)=\frac{\beta}{\eta}\left(\frac{t}{\eta}\right)^{\beta-1}
$$

The risk function $h(t)$ is the conditional probability of functional equipment failure at instant $(t+\Delta t)$, given by $[5,43]$ :

$$
h(t)=\left(\frac{\beta}{\lambda}\right)\left(\frac{t_{i}}{\lambda}\right)^{\beta-1}
$$

However, assessing the reliability of an equipment requires obtaining information on its components, which relates to failure events that occurred during the operation or testing of this equipment [17, 21, 29, 36-37, 44, 48]. In practice, for the turbine studied, this approach consists in observing for a certain operating time in the actual operating conditions of the gas turbine, in order to list all the information related to their failures. This is reliability data that requires the overall knowledge of turbine system and their operating conditions.

\subsection{Proposed modified weibull distribution}

The proposed model is the Weibull model with a variable shape parameter $\beta$, this shape parameter is proposed as a variable function over time, gradually increases to reach the maximum reliability, during the early life period, then begins an accelerated growth during the wear life period. Hence, the density function of the proposed model is given by:

$$
f(t)=\left(\frac{t}{d}\right)^{\beta(t)} e^{-\left(\frac{t}{d}\right)^{\beta(t)}}\left(\log \left(\frac{t}{d}\right)\left(\beta^{\prime}(t)\right)+\frac{\beta(t)}{t}\right)
$$

Where $\beta(t)$ is the variable form parameter and $d$ represents the scale parameter of the distribution. This function represents a family of densities, based on the Weibull model where its shape parameter $\beta$ is replaced by a known mathematical function proposed by Farazdaghi and Harris, given by:

$$
\beta(t)=\frac{1}{a+b(t / c)^{d}}
$$

And the distribution function of the model will be determined by the following form:

$$
F(t)=1-e^{-\left(\frac{t}{d}\right)^{\beta(t)}}
$$

In this case and with the use of the FarazdaghiHarris model for the nonlinear fit of reliability data, the probability density model becomes:

$f(t)=\left(\frac{t}{d}\right)^{\frac{1}{a+b(t / d)^{c}}} e^{-\left(\frac{t}{d}\right)^{\frac{1}{a+b(t / d)^{c}}}}\left(\frac{1}{t\left(a+b\left(\frac{t}{d}\right)^{c}\right)}-\frac{b c\left(\frac{t}{d}\right)^{c} \log \left(\frac{t}{d}\right)}{t\left(a+b\left(\frac{t}{d}\right)^{c}\right)^{2}}\right)$

$$
\text { with } \beta^{\prime}(t)=-\frac{b c\left(\frac{t}{d}\right)^{c}}{t\left(a+b\left(\frac{t}{d}\right)^{c}\right)^{2}} \text {. }
$$

To determine the given values taken for the turbine reliability analysis under consideration, the cumulative probability yields the following distribution function:

$$
F(t)=1-e^{-\left(\frac{t}{d}\right)^{\left(\frac{1}{a+b(t / d)^{c}}\right)}}
$$

Hence, the survival function is given by:

$$
S(t)=e^{-\left(\frac{t}{d}\right)^{\left(\frac{1}{a+b(t / d)^{c}}\right)}}
$$

And finally the risk function is given by:

$$
\begin{aligned}
h(t)= & \frac{f(t)}{S(t)}=\left(\frac{t}{d}\right)^{\frac{1}{a+b(t / d)^{c}}} \frac{1}{t\left(a+b\left(\frac{t}{d}\right)^{c}\right)} \\
& \left(1-\frac{b c\left(\frac{t}{d}\right)^{c} \log \left(\frac{t}{d}\right)}{\left(a+b\left(\frac{t}{d}\right)^{c}\right)}\right)
\end{aligned}
$$

This proposed modified Weibull distribution will be used as a result of this work, to model failure behavior, the next failure of a gas turbine and to plan their maintenance tasks.

\section{STUDIED GAS TURBINE}

The Hassi R'mel natural gas compression center, installed in the southern Algeria, uses MS5002C type gas turbines. This gas compression center is part of a group of stations and gas pipeline centers responsible for the activity of transporting gas through pipelines, for the transport, storage and delivery of liquid and gaseous hydrocarbons. The objective of this gas compression center is to set up high gas compression capacities, in order to accompany the natural drop in the pressure of the Hassi R'mel deposit, consists of increasing the gas pressure by means of turbochargers in order to maintain the nominal operating pressures of the Hassi R'mel treatment facilities. With a production capacity of 2,400 billion cubic meters of natural gas, this Hassi R'mel deposit is classified as the largest deposit in Africa.

However, the gas turbine studied in this work is an MS5002C model. Its specifications and characteristics are given in Table 1. It is composed of three elements, as it is mounted in Figures 1 and 2. An axial compressor, which plays the role of compressing the ambient air to a pressure between 10 and 30 bars approx. A combustion chamber, into which gaseous or liquid fuel is injected under pressure. A compressed air burner, with a strong excess of air to limit the temperature of the exhaust gases and the turbine itself, in which the gases that leave the combustion chamber are expanded.

The MS 5002C turbine is implemented for the two-shaft drive of an axial centrifugal compressor in a single cycle, using a Mark V SPEEDTRONIC control system, for the protection of this machine against over speed, overheating, vibration and flame detection. The portion of a mechanically driven gas turbine is the part where fuel oil and air are used to produce power on the shaft. This turbine has two mechanically independent turbine wheels. The high pressure first stage turbine wheel, drives the rotor of the air compressor, of the sixteen-stage axial type, and the shaft driving the accessories; Lubrication 


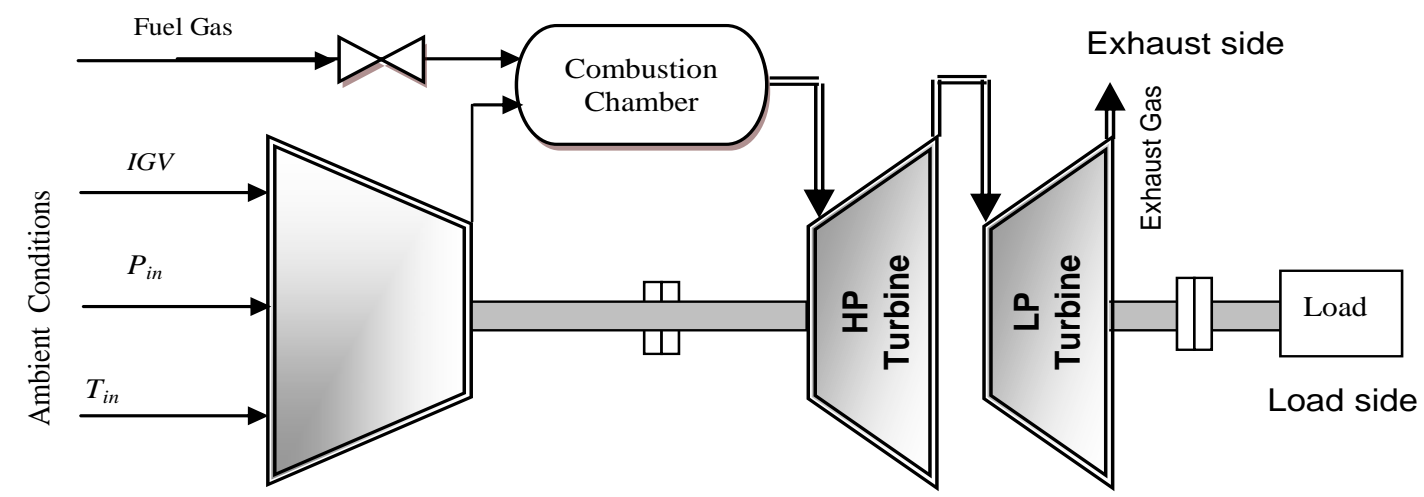

Fig. 1. Functional diagram of a gas turbine with two shafts

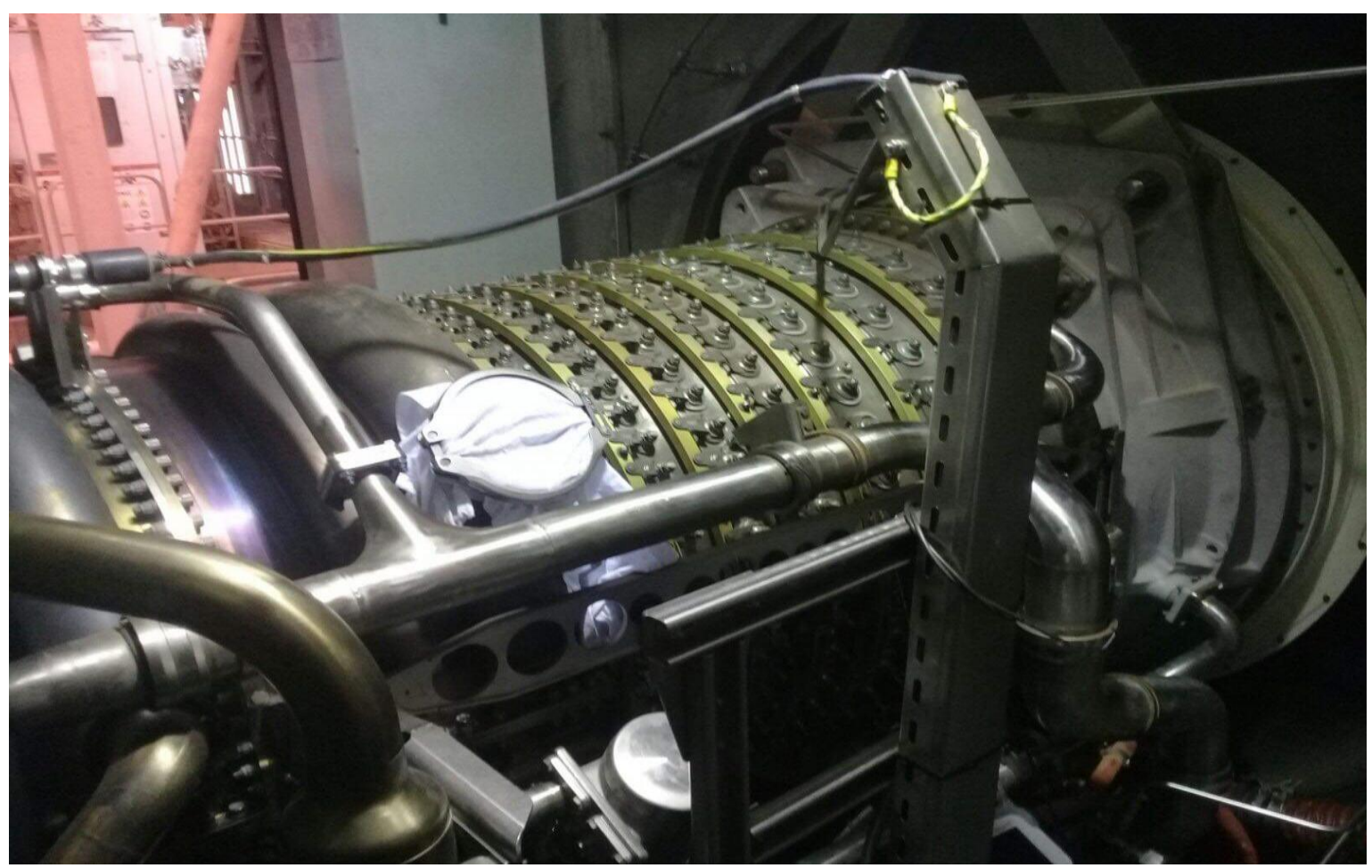

Fig. 2. Examined gas turbine MS5002C twin-shaft type

Table 1. Gas turbine MS5002C characteristics

\begin{tabular}{|c|c|c|c|}
\hline $\begin{array}{l}\text { Gas turbine model } \\
\text { MS5002C }\end{array}$ & Specifications & Turbine section & Specifications \\
\hline Power & $28.340 \mathrm{MW}$ & Number of stage & 2 \\
\hline Efficiency & $28.8 \%-29.2 \%$ & Shaft engine & Twin \\
\hline Heat rate & $12.467 \mathrm{~kJ} / \mathrm{kWh}$ & Joint plane & Horizontal \\
\hline Exhaust temperature & $517^{\circ} \mathrm{C}$ & Bearing assembly & 04 bearings \\
\hline Exhaust mass flow & $124.3 \mathrm{~kg} / \mathrm{s}$ & Lubrication Type & Under pressure \\
\hline LP shaft speed & $4900 \mathrm{rpm}$ & HP shaft speed & $5100 \mathrm{rpm}$ \\
\hline Combustion section & Specifications & Compressor section & Specifications \\
\hline $\begin{array}{l}\text { Number of combustion } \\
\text { chambers }\end{array}$ & 12 with reverse flow & Number of stage & 16 \\
\hline Chambers configuration & $\begin{array}{c}\text { Concentric around the } \\
\text { compressor }\end{array}$ & Flow type axial & Heavy series \\
\hline Spark plugs & $\begin{array}{l}2 \text { types of self-retracting } \\
\text { spring injection electrode }\end{array}$ & Joint plane & horizontal flange \\
\hline Flame detector & 4 ultraviolet type & Type of guide vanes at the inlet & Variable \\
\hline
\end{tabular}


and hydraulic pumps. The impeller of the second stage turbine, or low pressure stage, drives the load which is a centrifugal compressor. The two impellers of the turbine are not linked to allow them to rotate at different speeds to adapt to variations in load. The use of two separate turbine wheels allows the two shafts to rotate at different speeds to meet the varying load requirements of the centrifugal compressor while allowing the high pressure gas generator to operate at the rated speed of the axial compressor. This MS 5002C gas turbine is composed of the suction or admission side, the combustion part and the exhaust part with isentropic expansion in the high pressure HP turbine wheels and in the low pressure LP turbine.

So this gas turbine extracts air from the surrounding environment at a higher pressure, it increases the energy level of the compressed air by adding and burning the fuel in a combustion chamber. This machine conveys air at high pressure and temperature to the turbine section, which converts thermal energy into mechanical energy to rotate the shaft, this serves on the one hand to supply the useful energy to the machine pipe coupled with the machine by means of a coupling and on the other side to provide the energy necessary for compression, which takes place in a compressor connected directly to the turbine section.

Indeed, the reliability analysis is an essential phase for the operational safety analysis, for quality and for decision support in maintenance. The following section presents the MS5002C turbine reliability data processing and analysis phase examined. This lies in taking into account all the information related to the failures of this machine, during an observation period to represent their useful life and degradations. This failure rate-based analysis makes it possible to explain a phenomenon of degradation of the turbine components examined as best as possible and makes it possible to formulate hypotheses for the maintenance actions to be programmed for this rotating machine.

\subsection{Reliability data of the examined MS5002C turbine}

To meet the performance, safety and availability objectives of gas turbine processes, they are associated with a reliability and availability improvement system that serves to detect any deviation of behavior from the desired behavior and even in certain situations. reconfigure the operation of the system. These systems use modern data acquisition and processing technologies, as shown in Figure 3, for improved availability and operating quality of this type of machine.

Therefore, the analysis of operating data is essential for the development of turbine reliability models. For this, a series of operating history data from the examined MS5002C gas turbine, presented in Table 2, are used for the analysis and determination of the various reliability indices of this machine. Using Sturge's rule for a sample of size $\mathrm{N}$ $=246$, to first perform a division into classes of the turbine data, as follows:

$$
K \geq 1+\frac{10}{3} \log N
$$

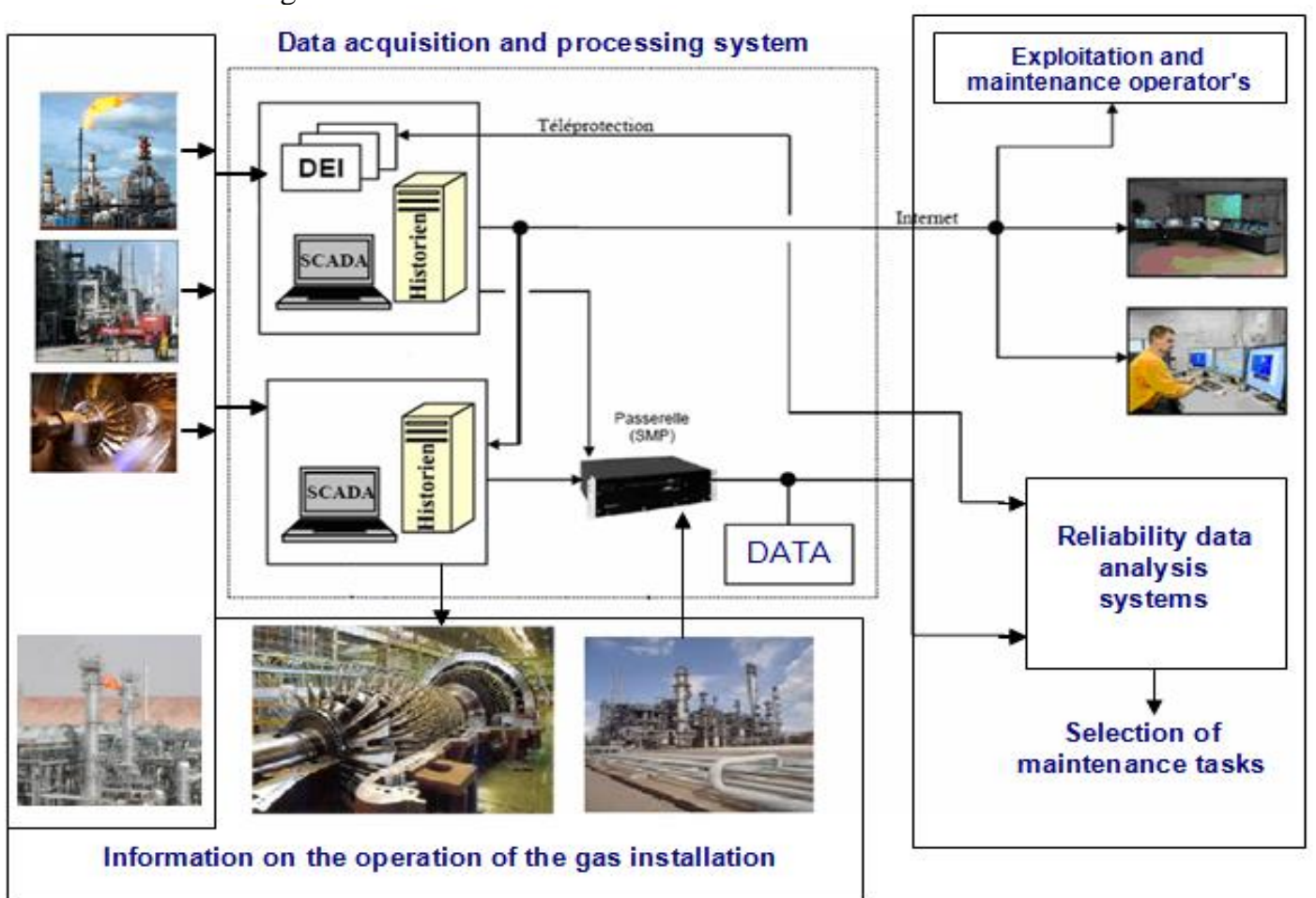

Fig. 3. Gas compressor station data acquisition and processing system 
Table 2. Operating history data for the examined MS5002C gas turbine

\begin{tabular}{cccccc}
\hline & & \multicolumn{3}{c}{ MS5002C gas turbine } \\
\hline $\mathrm{N}^{\circ}$ & Classes & $\mathrm{N}$ & $\mathrm{f}$ & $\mathrm{F}$ & $\mathrm{Fa}$ \\
\hline 1 & {$[0,82[$} & 132 & 0,545454545 & 0,545454545 & 0.5433884 \\
\hline 2 & {$[82,164[$} & 55 & 0,227272727 & 0,772727273 & 0.7706612 \\
\hline 3 & {$[164,246[$} & 23 & 0,095041322 & 0,867768595 & 0.8657025 \\
\hline 4 & {$[246,328[$} & 14 & 0,05785124 & 0,925619835 & 0.9235537 \\
\hline 5 & {$[328,418[$} & 7 & 0,02892562 & 0,954545455 & 0.9524793 \\
\hline 6 & {$[418,492[$} & 3 & 0,012396694 & 0,966942149 & 0.9648760 \\
\hline 7 & {$[492,574[$} & 5 & 0,020661157 & 0,987603306 & 0.9855372 \\
\hline 8 & {$[574,656[$} & 1 & 0,004132231 & 0,991735537 & 0.9896694 \\
\hline 9 & {$[656,738[$} & 2 & 0,008264463 & 1 & 0.9979339 \\
\hline
\end{tabular}

\subsection{Graphical reliability method}

To address the problem of determining if a dataset can be adequately modeled by reliability distributions, by observing a class of data, especially through data from failures in that class of data. This makes it possible to build a database which contributes to the various maintenance interventions of this machine, to correctly model this class of turbine data examined, the graphical plot of Weibull paper WPP based on a data set is made by the graphical method. This is for the two-parameter Weibull model, as shown in Figure 4, as well as for the proposed modified Weibull model, as shown in Figure 5.

The graphical plot of Weibull paper WPP consists in plotting the variable $y$ with respect to the variable $\mathrm{x}$, where these are related by the Weibull transformation, as follows:

$$
\begin{aligned}
& \left\{\begin{array}{c}
y=\ln [-\ln (\bar{F}(t))] \\
x=\ln (t)
\end{array}\right. \\
\Rightarrow & \left\{\begin{array}{c}
y=\beta x-\beta \log (\alpha) \\
x=\log (t)
\end{array}\right.
\end{aligned}
$$

It is a linear form $y=a x+b$, which implies that $y=0.8608 x-08608 \log (109.5)$.

For the modified Weibull distribution, the plot of the variable $y$ against the variable $x$ is given by the following form :

$$
\begin{gathered}
\left\{\begin{array}{c}
y=\log (\alpha)+\beta x+\lambda e^{x} \\
x=\log (t)
\end{array}\right. \\
\Rightarrow y=a+b x+\lambda \log (x)
\end{gathered}
$$

It is a nonlinear form, which implies that $y=$ $\log (0.03088)+0.734 x+0.00042 \log (x)$.

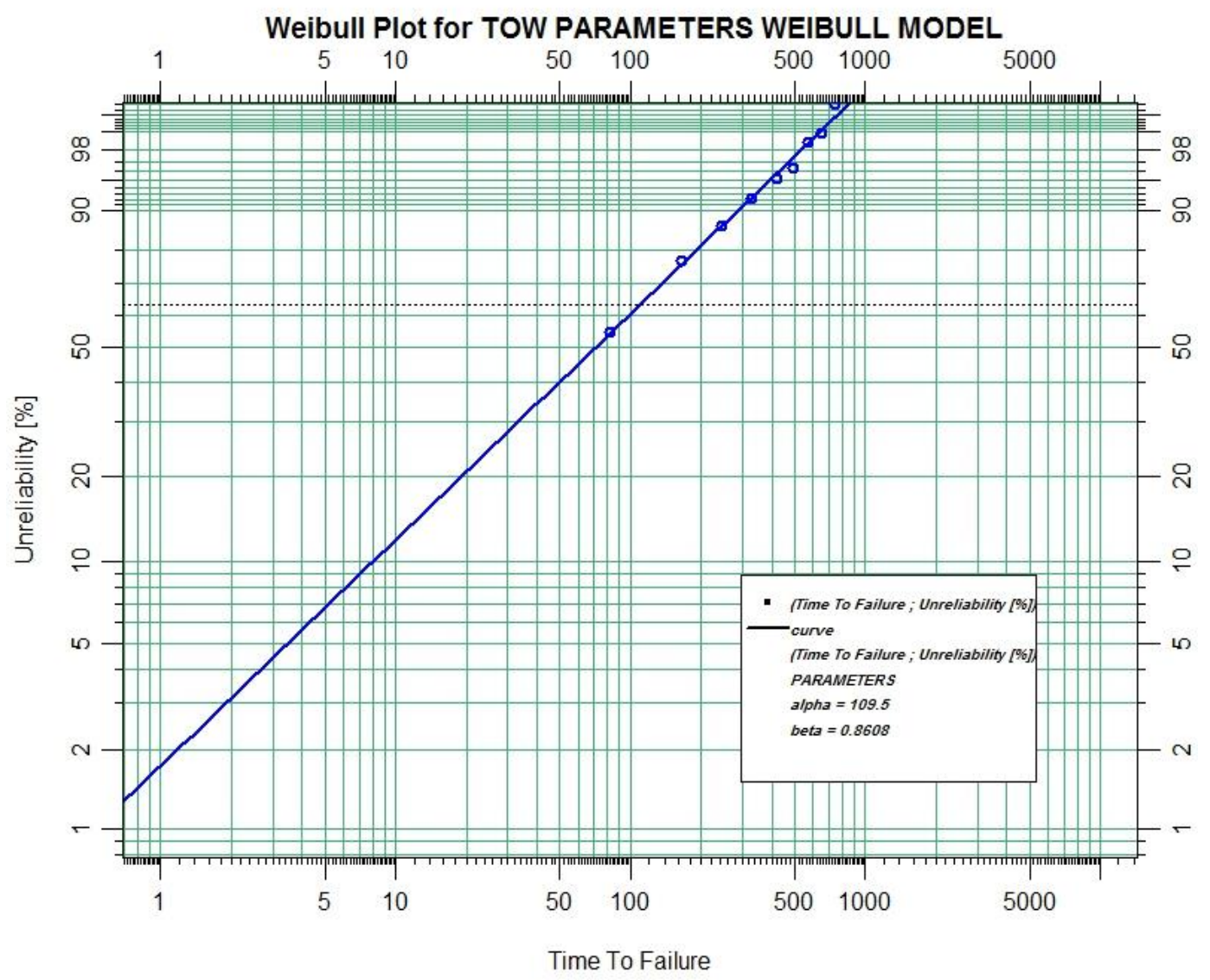

Fig. 4. Graphical plot of Weibull paper WPP for the examined turbine reliability model based on two-parameter Weibull 


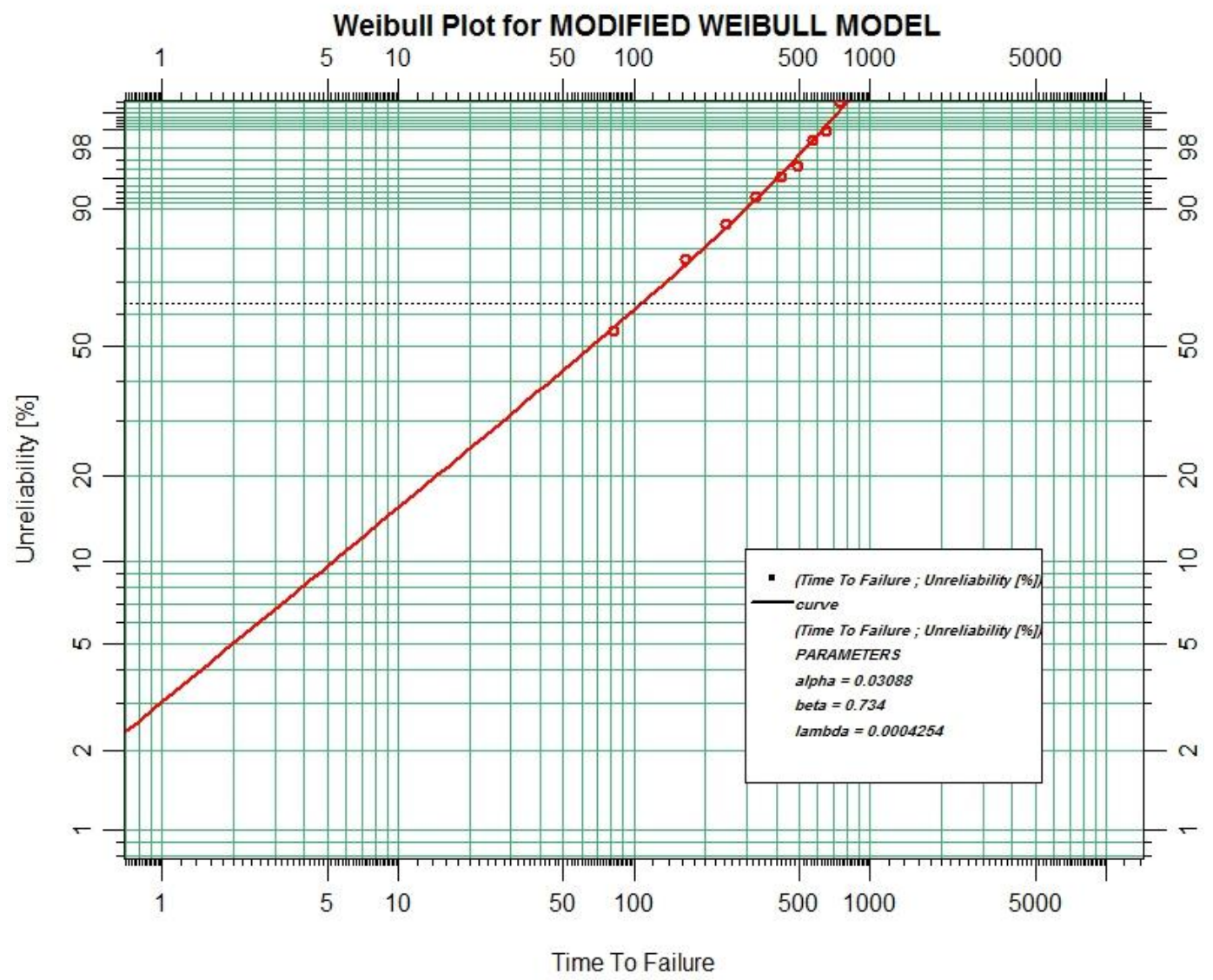

Fig. 5. Graphical plot of Weibull paper WPP for the examined turbine reliability model based on modified Weibull

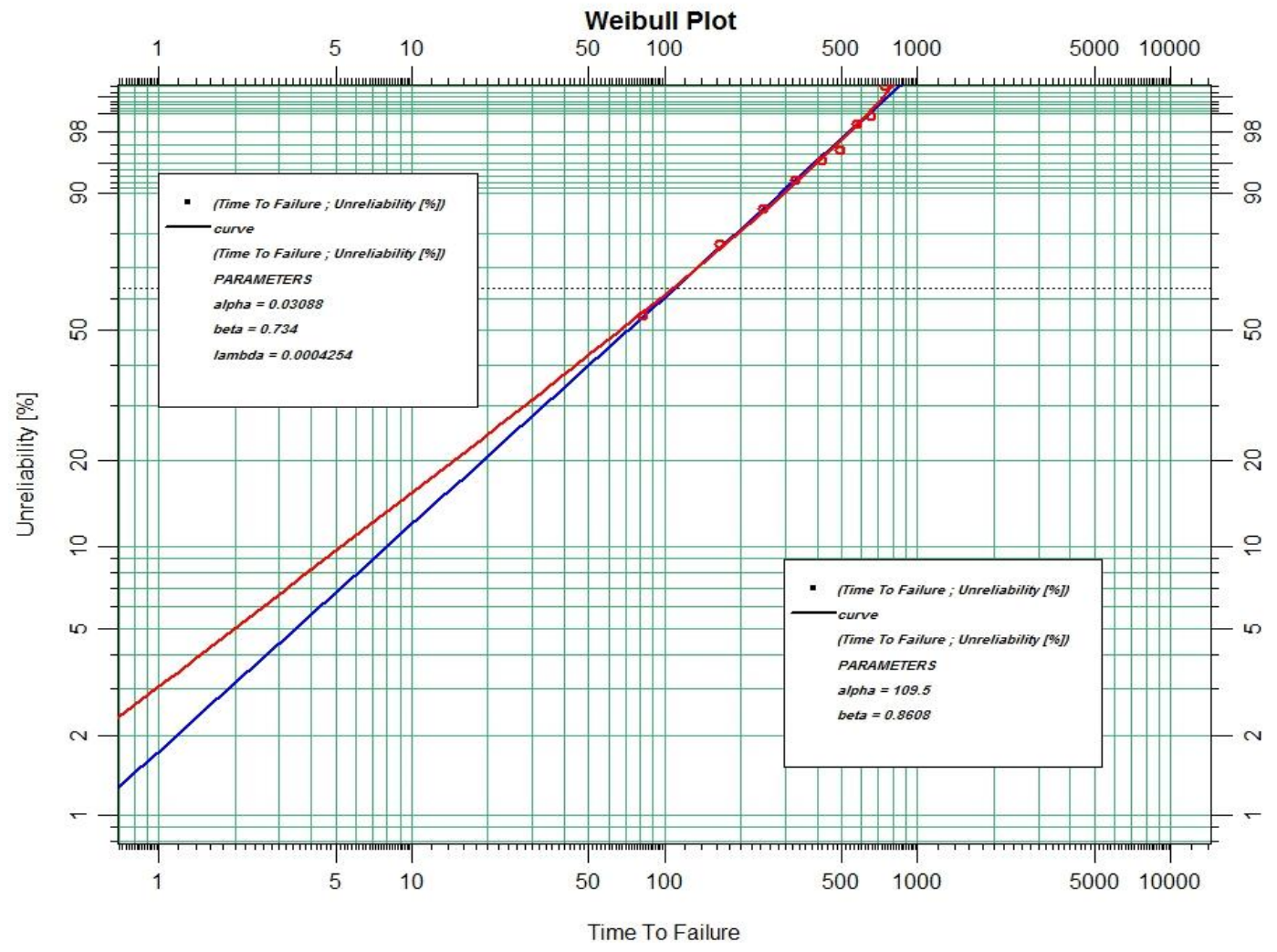

Fig. 6. Comparison of graphical plots of Weibull WPP paper for the examined turbine reliability model based on two-parameter Weibull and modified Weibull 
This graphing technique is used to determine whether a dataset comes from a population, examined gas turbine failure data class, which would logically be fitted by a Weibull distribution. Subsequently, several statistical tests will be carried out to confirm the choice of the reliability distribution for the examined turbine case.

\section{STATISTICAL ESTIMATE OF RELIABILITY INDEX}

Reliability measures are determined by the probability of survival of a system, can be applied when reliability distributions are well-chosen, to characterize measures composed of various failing elements in the system. In this sense, statistical estimates based on the maximum likelihood, the method of moments, the non-parametric regression method of the percentiles, and the method of the least-squares will be performed to determine the best suitable distribution for the turbine system under consideration.

\subsection{Maximum likelihood estimation}

The lifespan of a system can be modeled by a two-parameter Weibull distribution, using complete data observed during system operation. For the turbine case studied, the likelihood seems to contain all the information provided by the observations during their operation, based on the good asymptotic properties of this estimator. Hence, the likelihood algorithm is given by:

$$
\begin{aligned}
& L=\prod_{i=1}^{N} f\left(x_{i}, \lambda, \beta\right) \\
& \frac{\partial \ln (L)}{\partial \lambda}=0, \quad \frac{\partial \ln (L)}{\partial \beta}=0
\end{aligned}
$$

With $C=\frac{N !}{\bigsqcup_{i=1}^{N R} n_{i} !} \quad$ and $\quad P\left(x_{i-1} \prec X \leq x_{i}\right)=$ $F\left(x_{i}\right)-F\left(x_{i-1}\right)$
$\Rightarrow P\left(x_{i-1} \prec X \leq x_{i}\right)=\bar{F}\left(x_{i}\right)-\bar{F}\left(x_{i-1}\right)$.Then the maximum likelihood estimator of a random variable $X$ governed by a probability $P$ is determined by the set of absolutely continuous probability measures $L$ with respect to a failure measure $\lambda$ is given by:

$$
\begin{aligned}
& L\left(x_{1}, x_{2}, x_{3}, \ldots, \beta, \lambda\right)=C \prod_{i=1}^{N R}\left[\bar{F}\left(x_{i}\right)-\bar{F}\left(x_{i-1}\right)\right]^{n_{i}} \\
& =C \prod_{i=1}^{N R}\left[e^{\left[-\left(\frac{x_{i}}{\lambda}\right)^{\beta}\right]}-e^{\left[-\left(\frac{x_{i-1}}{\lambda}\right)^{\beta}\right]}\right]^{n_{i}} \\
& \Rightarrow \ln \left[L\left(x_{1}, x_{2}, x_{3}, \ldots, \beta, \lambda\right)\right]=\ln C+ \\
& \sum_{i=1}^{N R} n_{i} \ln \left[e^{\left[-\left(\frac{x_{i}}{\lambda}\right)^{\beta}\right]}-e^{\left[-\left(\frac{x_{i-1}}{\lambda}\right)^{\beta}\right]}\right] \\
& \text { With } A_{i}(\theta)=\left\{\begin{array}{c}
0 \quad \text { if } i=0 \\
e^{\left[-\left(\frac{x_{i}}{\lambda}\right)^{\beta}\right]} \quad \text { if } i=1, \ldots, N R \\
0 \quad \text { if } i=N R+1
\end{array}\right.
\end{aligned}
$$

We get:

$$
\begin{gathered}
L\left(x_{1}, x_{2}, x_{3}, \ldots, \beta, \lambda\right)=C \prod_{i=1}^{N R}\left[P \left(x_{i-1} \prec X \leq\right.\right. \\
\left.\left.x_{i}\right)\right]^{n_{i}}
\end{gathered}
$$

partial derivative of logarithms of equation (16), with respect to $\lambda$ gives the estimation equations of

$$
\begin{gathered}
\frac{\partial \ln (L)}{\partial \lambda}= \\
-\sum_{i=1}^{N R} n_{i} \frac{A_{i-1}\left[\left(\frac{x_{i-1}}{\lambda}\right)^{\beta} \ln \left(\frac{x_{i-1}}{\lambda}\right)-A_{i}\left[\left(\frac{x_{i}}{\lambda}\right)^{\beta} \ln \left(\frac{x_{i}}{\lambda}\right)\right]\right]}{A_{i-1}-A_{i}}
\end{gathered}
$$

This makes it possible to have the new numerical estimation results of $\hat{\beta}=0.8694809$ and $\hat{\lambda}=$ 107.6626769. This maximum likelihood estimator gives good results, as it is shown in Figure 7, despite the limitations of the precision of the measurements, according to which, all the information on the evolution of failures is contained in the likelihood function, during the turbine observation period.

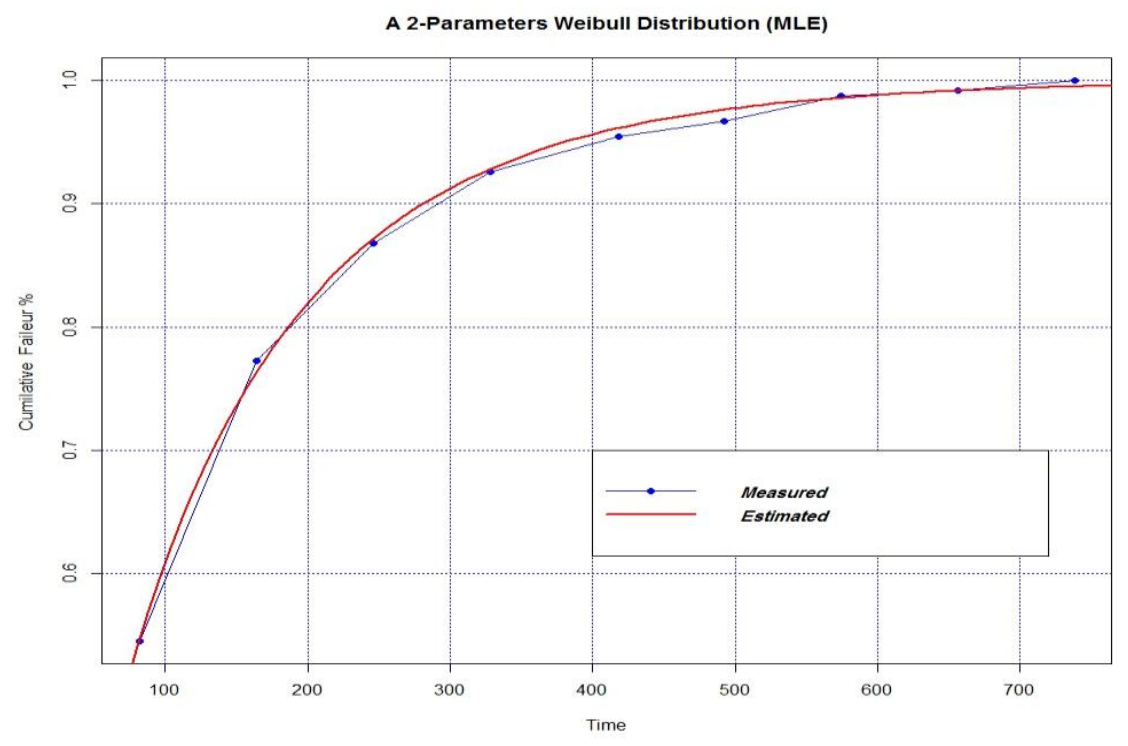

Fig. 7. Evolution of two-parameter Weibull-based turbine failures with maximum likelihood estimator 
For the case of the modified Weibull distribution proposed in this work, the likelihood function is easy to determine, for the complete data of the turbine, this function is given by:

$$
\begin{gathered}
L=\prod_{\substack{i=1 \\
N}}^{N} f\left(x_{i}, a, b, \lambda\right) \\
\frac{\partial \ln (L)}{\partial a}=0, \quad \frac{\partial \ln (L)}{\partial b}=0, \frac{\partial \ln (L)}{\partial \lambda}=0
\end{gathered}
$$

Where,

$$
\begin{aligned}
& L\left(x_{1}, x_{2}, x_{3}, \ldots, a, b, \lambda\right) \\
& =C \prod_{i=1}^{N R}\left[P\left(x_{i-1} \prec X \leq x_{i}\right)\right]^{n_{i}} \\
& =C \prod_{i=1}^{N R}\left[\bar{F}\left(x_{i}\right)-\bar{F}\left(x_{i-1}\right)\right]^{n_{i}}
\end{aligned}
$$$$
=C \prod_{i=1}^{N R}\left[e^{\left[-a t^{b} e^{\left(\lambda x_{i-1}\right)}\right]}-e^{\left[-a t^{b} e^{\left(\lambda x_{i}\right)}\right]}\right]^{n_{i}}
$$

We can get :

$$
\ln \left[L\left(x_{1}, x_{2}, x_{3}, \ldots, a, b, \lambda\right)\right]
$$

$=\ln C+\sum_{i=1}^{N R} n_{i}\left[e^{\left[-a t^{b} e^{\left(\lambda x_{i-1}\right)}\right]}-\right.$

$\left.e^{\left[-a t^{b} e^{\left(\lambda x_{i}\right)}\right]}\right]$ With $A_{i}(\theta)=$

$\left\{\begin{array}{c}0 \quad \text { if } i=0 \\ e^{\left[-a t^{b} e^{\left(\lambda x_{i}\right)}\right]} \text { if } i=1, \ldots, N R . \\ 0 \quad \text { if } i=N R+1\end{array}\right.$

However, the results obtained for the proposed failure model of the modified Weibull distribution, shown in Figure 8, give estimated values $\hat{a}=$ 0.0254027, $\hat{b}=0.7754443$ and $\hat{\lambda}=$ 0.000397175 with perfect fit, obtained with respect to the partial derivative, given by :

$$
\begin{aligned}
& \frac{\partial \ln (L)}{\partial a}=-\sum_{i=1}^{N R} n_{i} \\
& \frac{A_{i-1}\left[\left(x_{i-1}\right)^{b} e^{\left(\lambda x_{i-1}\right)}\right]-A_{i}\left[\left(x_{i}\right)^{b} e^{\left(\lambda x_{1}\right)}\right]}{A_{i-1}-A_{i}} \\
& \frac{\partial \ln (L)}{\partial b}=-\sum_{i=1}^{N R} n_{i} \\
& \frac{A_{i-1}\left[a\left(x_{i-1}\right)^{b} \ln \left(x_{i-1}\right) e^{\left(\lambda x_{i-1}\right)}\right]-A_{i}\left[a\left(x_{i}\right)^{b} \ln \left(x_{i}\right) e^{\left(\lambda x_{i}\right)}\right]}{A_{i-1}-A_{i}} \\
& \frac{\partial \ln (L)}{\partial \lambda}=\sum_{i=1}^{N R} n_{i} \\
& \frac{A_{i-1}\left[-a\left(x_{i-1}\right)^{b+1} e^{\left(\lambda x_{i-1}\right)}\right]-A_{i}\left[-a\left(x_{i}\right)^{b+1} e^{\left(\lambda x_{i}\right)}\right]}{A_{i-1}-A_{i}}
\end{aligned}
$$

\subsection{Estimation based on the method of moments}

In the case of the two-parameter Weibull distribution, using an estimator based on the method of moments, in which the failure variable expectation $\lambda$ is dependent, for each observation $t_{i}$ is a draw from an expectation distribution law $m_{k}$, which is an unbiased estimator for the time $K^{\text {th }}$ given by:

$$
\widehat{m}_{k}=\sum_{i=1}^{N} t_{i}^{k}
$$

For the Weibull distribution case, the moment $K^{\text {th }}$ is given as follows:

$$
\mu_{k}=\left(\frac{1}{\lambda^{\beta}}\right)^{\frac{k}{-\beta}} \Gamma\left(1+\frac{k}{\beta}\right)
$$

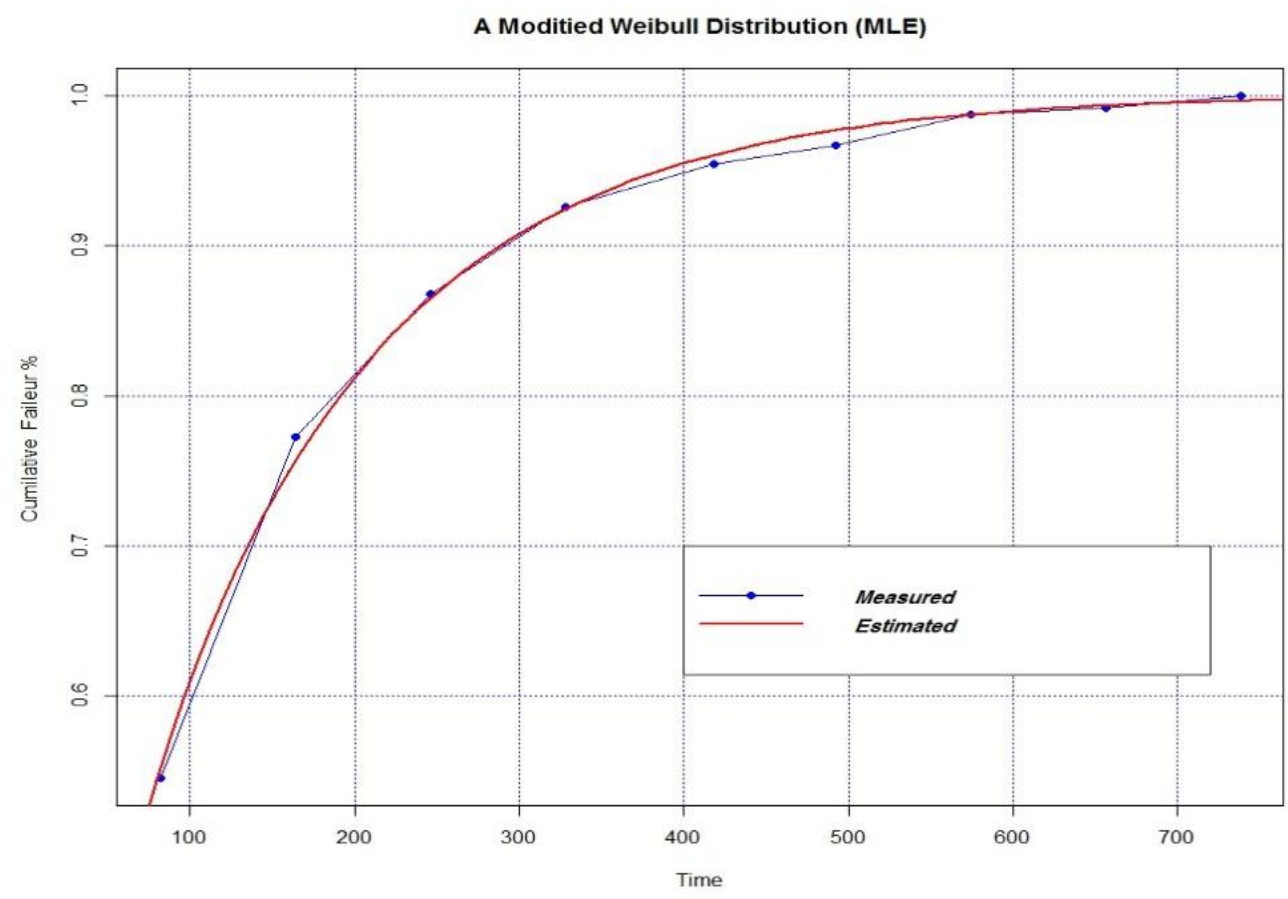

Fig. 8. Evolution of modified Weibull-based turbine failures with maximum likelihood estimator 
Hence $\Gamma$ means the gamma function, determined as follows:

$$
\begin{aligned}
& \Gamma(s)=\int_{0}^{\infty} x^{s-1} e^{-s} d x, s>0 \\
& m_{1}=\mu_{1}=\left(\frac{1}{\lambda}\right)^{\frac{1}{\beta}} \Gamma\left(1+\frac{1}{\beta}\right) \\
& m_{2}=\mu_{2}+\mu_{1}^{2}=\sigma^{2}+m_{1}^{2} \\
& =\left(\frac{1}{\lambda}\right)^{\frac{2}{\beta}}\left[\Gamma\left(1+\frac{2}{\beta}\right)+\Gamma\left(1+\frac{1}{\beta}\right)^{2}\right] \\
& \Rightarrow \sigma^{2}=m_{2}-m_{1}^{2} \\
& =\left(\frac{1}{\lambda}\right)^{\frac{2}{\beta}}\left[\Gamma\left(1+\frac{2}{\beta}\right)+\Gamma\left(1+\frac{1}{\beta}\right)^{2}\right] \\
& \hat{\sigma}^{2}=\frac{\left(\frac{1}{\lambda}\right)^{\frac{2}{\beta}}\left[\Gamma\left(1+\frac{2}{\beta}\right)+\Gamma\left(1+\frac{1}{\beta}\right)^{2}\right]}{\hat{\mu}^{2}}=\frac{\left(\frac{1}{\lambda}\right)^{\frac{2}{\beta}} \Gamma^{2}\left(1+\frac{1}{\beta}\right)}{\Rightarrow C V=\sqrt{\frac{\hat{\sigma}^{2}}{\hat{\mu}^{2}}}}
\end{aligned}
$$

For the turbine data examined, Figure 9 shows the evolution of failures of this Weibull-based machine with two parameters with estimator of the method of moments, with the estimate $\hat{\beta}=$ 0.9625049 and $\hat{\lambda}=120.1602$, given by :

$$
\sigma=\sqrt{\left(\sum_{i=1}^{N} p_{i} x_{i}^{2}\right)-\bar{x}^{2}}
$$

with $\bar{x}=\sum_{i=1}^{N} p_{i} x_{i}$ and $C V=\frac{\sigma}{\bar{x}}$

For the modified Weibull distribution, it is not possible to use the method of moments to estimate the parameters of the distribution because the expressions of the moments are analytically insolvent.

\subsection{Estimate based on the nonparametric percentile regression method}

For the cumulative failure probability, the estimate based on the nonparametric regression method of percentiles of a population of reliability data $0 \prec P \prec 1$, using the two-parameter Weibull model of a two-parameter Weibull population is $100 P \%$ of the percentile $x_{p}$, is given by:

$$
x_{p}=\lambda=[-\ln (1-P)]^{1 / \beta}
$$

For a sample size $n$, the $100 P \%$ percentile of $x_{p}$ with:

$\hat{x}_{p}=\left\{\begin{array}{c}x_{n p: n} \text { if } n p \text { is an int e ger } \\ x_{[n p]}+1: n \text { if } n p \text { is not int } e \text { ger }\end{array}\right.$.

We get:

$$
\ln [-\ln (1-P)]=\beta\left(\ln x_{p}-\ln \lambda\right)
$$

For two real numbers $P_{1}$ and $P_{2}$ such that $0 \prec$ $P_{1} \prec P_{2} \prec 1$, we have:

$$
\begin{aligned}
& \left\{\begin{array}{l}
\ln \left[-\ln \left(1-P_{1}\right)\right]=\beta\left(\ln x_{p_{1}}-\ln \lambda\right) \\
\ln \left[-\ln \left(1-P_{2}\right)\right]=\beta\left(\ln x_{p_{2}}-\ln \lambda\right)
\end{array}\right. \\
& \Rightarrow \beta=\frac{\ln \left[-\ln \left(1-P_{1}\right)\right]-\ln \left[-\ln \left(1-P_{2}\right)\right]}{\ln x_{p_{1}}-\ln x_{p_{2}}}
\end{aligned}
$$

Consequently, a percentile estimator of $\beta$, based on two ordered sample values, is given by:

$$
\hat{\beta}=\frac{\ln \left[-\ln \left(1-P_{1}\right)\right]-\ln \left[-\ln \left(1-P_{2}\right)\right]}{\ln x_{p_{1}}-\ln x_{p_{2}}}
$$

Both probability $P_{1}$ and $P_{2}$ are selected to minimize the variance of $\hat{\beta}$, where 17 th and 97 th percentiles of the turbine failure data sample studied, is determined by:

$$
\lambda=e^{\left(w \ln y_{1}+(1-w) \ln y_{2}\right)}
$$

with $w=1-\frac{\ln \left[-\ln \left(1-P_{1}\right)\right]}{\ln \left[-\ln \left(1-P_{1}\right)\right]-\ln \left[-\ln \left(1-P_{2}\right)\right]}$.

The variance of failures $\hat{\lambda}$ is determined after selecting two probability $P_{1}$ and $P_{2}$ at the 40th and 82 nd percentiles of the minimized sample of turbine failure data studied, the results obtained for this percentile is shown in Figure 10, allows to estimate $\hat{\lambda}=100.0366$ for the probabilities $P_{1}=$ 0.5433168 and $P_{2}=0.9872112$. And for the estimated value $\hat{\beta}=0.7809538$ for the probabilities $P_{1}=0.8626238$ and $P_{2}=0.9773102$.

For the evolution of turbine failures with nonparametric regression method estimator of the modified Weibull probability $100 P \%$ using $x_{p}$ percentiles of the data population studied is given by:

$$
\begin{aligned}
& \quad P=1-e^{-a t e^{\left(\lambda x_{p}\right)}} \\
& \text { with } \\
& =\ln \left[-\ln \left(1-P_{i}\right)\right], i=1,2
\end{aligned}
$$

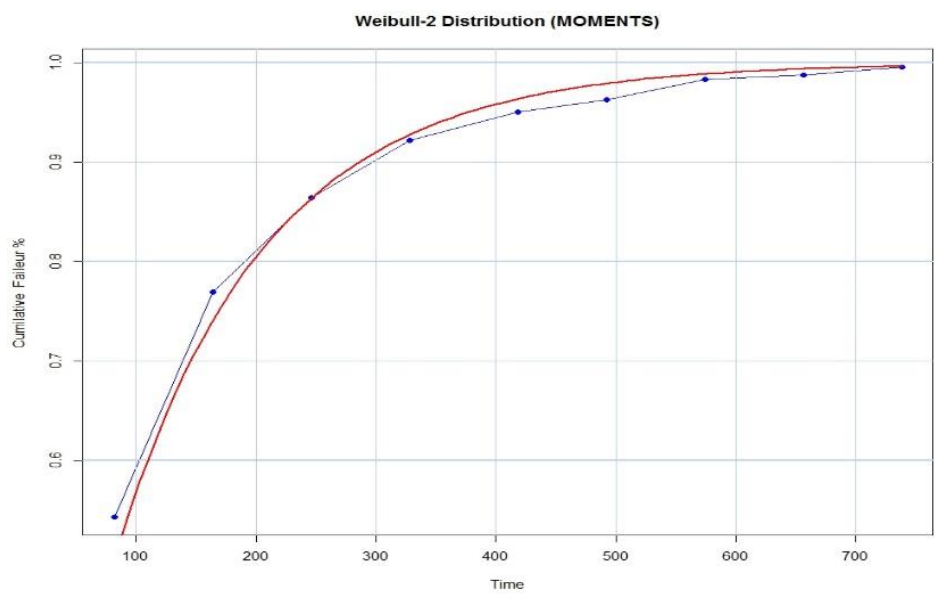

Fig. 9. Evolution of Weibull-based turbine failures with two parameters with estimator of the method of moments 


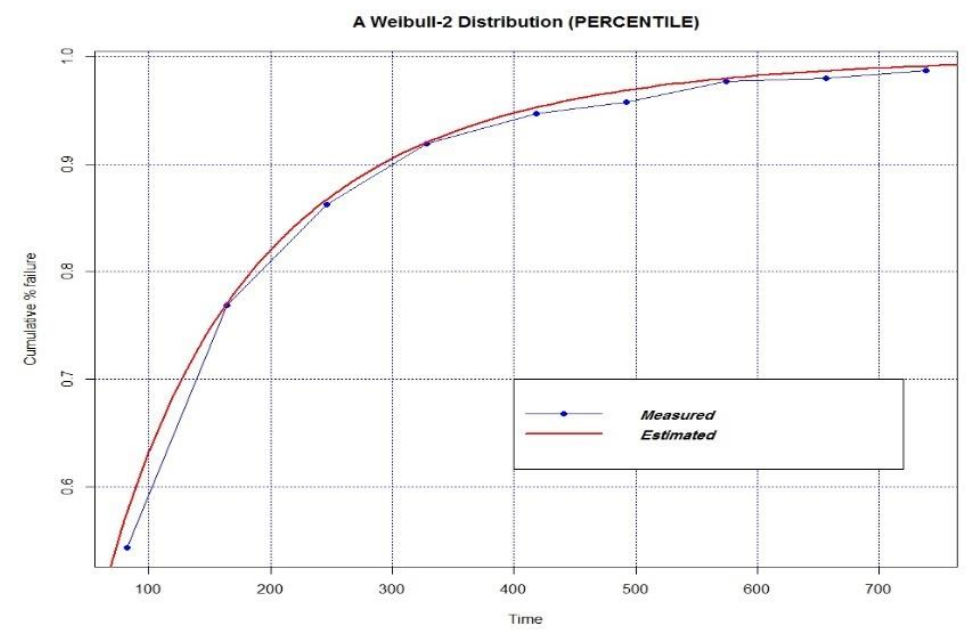

Fig. 10. Evolution of Weibull-based turbine failures with two parameters with estimator of the nonparametric regression method of the percentiles

By solving this equation, we determine the parameters $b$, as follows:

$$
\begin{gathered}
b=\frac{K_{12}-K_{13}}{Z_{12}-Z_{13}} \\
\text { with } K_{12}=\frac{\ln x_{p_{1}}-\ln x_{p_{2}}}{x_{p_{1}}-x_{p_{2}}}, K_{13}=\frac{\ln x_{p_{1}}-\ln x_{p_{3}}}{x_{p_{1}}-x_{p_{3}}} \\
Z_{12}=\frac{Z_{1}-Z_{2}}{x_{p_{1}}-x_{p_{2}}}, Z_{13}=\frac{Z_{1}-Z_{3}}{x_{p_{1}}-x_{p_{3}}} \\
\text { To determine the parameters } \lambda, \text { as follows: } \\
Z_{i}=\ln \left[-\ln \left(1-P_{i}\right)\right] \\
\lambda=Z_{13}-b K_{13}
\end{gathered}
$$

And to determine the parameters $a$, as follows:

$$
a=e^{\left(b \ln x_{p_{i}}+\lambda x_{p_{i}}-z_{1}\right)}
$$

After the selection of two probability, $P_{1}, P_{2}$ and $P_{3}$ percentiles of the minimized sample of turbine failure data studied, the results obtained for this percentile is shown in Figure 11, allows to estimate, $\hat{a}=0.01467593, \quad \hat{b}=0.9107816$ and $\hat{\lambda}=$ -0.0004348491 for the probabilities $P_{1}=$ $0.5433168, P_{2}=0.9872112$ and $P_{3}=0.8626238$.

\subsection{Estimation based on the least squares method}

For the Weibull two-parameter reliability model, the least-squares method compares actual turbine operating data with measurement errors on that data and minimizes the impact of these experimental errors. With linearization, we have:

$$
\begin{gathered}
y_{i}=F\left(x_{i}\right)=1-e^{\left[-\left(\frac{x_{i}}{\lambda}\right)^{\beta}\right]} \\
1-y_{i}=e^{\left[-\left(\frac{x_{i}}{\lambda}\right)^{\beta}\right]} \Rightarrow \ln \left(1-y_{i}\right)=-\left(\frac{x_{i}}{\lambda}\right)^{\beta}
\end{gathered}
$$

with $Y_{i}=\ln \left[-\ln \left(1-y_{i}\right)\right], X_{i}=\ln x_{i}, a=\beta$, $b=-\beta \ln \lambda$ and $Y_{i}=a X_{i}+b+\varepsilon$.

To minimize the sum of the error squares, it is necessary to solve the conditions $\frac{\partial S S E}{\partial a}=0$ and $\frac{\partial S S E}{\partial b}=0$, for the sum of the error squares which is given by:

$S S E=\sum_{i=1}^{N}\left(Y_{i}-\hat{Y}_{i}\right)^{2}=\sum_{i=1}^{N}\left(Y_{i}-\left(b+a X_{i}\right)\right)^{2}$
For that we have:

$$
\begin{aligned}
& \frac{\partial S S E}{\partial a}=\sum_{i=1}^{N} 2\left(Y_{i}-\left(b+a X_{i}\right)\right)\left(-X_{i}\right)=0 \\
& \frac{\partial S S E}{\partial b}=\sum_{i=1}^{N} 2\left(Y_{i}-\left(b+a X_{i}\right)\right)=0 \\
& \Rightarrow \sum_{i=1}^{N} Y_{i}-\sum_{i=1}^{N} b-a \sum_{i=1}^{N} X_{i}=0
\end{aligned}
$$$$
\frac{1}{N} \sum_{i=1}^{N} Y_{i}-a \frac{1}{N} \sum_{i=1}^{N} X_{i}=b \Rightarrow b=\bar{Y}-a \bar{X}
$$

By other way we have:

$$
\begin{gathered}
\sum_{i=1}^{N} Y_{i} X_{i}+b \sum_{i=1}^{N} X_{i}+a \sum_{i=1}^{N} X_{i}^{2}=0 \\
\Rightarrow a=\frac{-\sum_{i=1}^{N} Y_{i} X_{i}+\sum_{i=1}^{N} X_{i} \bar{Y}}{\sum_{i=1}^{N} X_{i} \bar{X}-\sum_{i=1}^{N} X_{i}^{2}}
\end{gathered}
$$

This least squares estimator makes it possible to develop the two-parameter Weibull-based approximation model, shown in Figure 12, with the estimates of the variables of $\hat{a}=104.6549$ and $\hat{b}=$ 0.7666161 .

To analyze the goodness of fit of Weibull-based turbine failure prediction modified with the least squares estimator, with the use of decomposing the sums of squares of the deviations from the mean of each value of $X$ corresponds the estimated value of $Y$, in the following form:

$$
\begin{aligned}
& y_{i}=F\left(x_{i}\right)=1-e^{\left(-a t e^{\left(\lambda x_{i}\right)}\right)} \\
& 1-y_{i}=e^{\left(-a t e^{\left(\lambda x_{i}\right)}\right)} \Rightarrow-\ln \left(1-y_{i}\right)=a x_{i}^{b} e^{\left(\lambda x_{i}\right)} \\
& Y_{i}=e_{0}+e_{1} X 1_{i}+e_{2} X 2_{i}+\varepsilon_{i}
\end{aligned}
$$

$$
\text { with } Y=\left(\begin{array}{c}
\ln \left[-\ln \left(1-y_{1}\right)\right] \\
n\left[-\ln \left(1-y_{2}\right)\right] \\
\vdots \\
\vdots \\
n\left[-\ln \left(1-y_{n}\right)\right]
\end{array}\right), e\left(\begin{array}{c}
e_{0} \\
e_{1} \\
e_{2}
\end{array}\right), \varepsilon=\left(\begin{array}{c}
\varepsilon_{1} \\
\varepsilon_{2} \\
\vdots \\
\varepsilon_{n}
\end{array}\right) \text {, }
$$

$\underset{n \times 3}{X}=\left(\begin{array}{ccc}1 & X 1_{1} & X 2_{2} \\ \vdots & \vdots & \vdots \\ 1 & X 1_{n} & X 2_{n}\end{array}\right), X 1_{i}=\ln \left(x_{i}\right)$ and $X 2_{i}=x_{i}$. 
The least squares estimator is given by:

$$
\hat{e}=S X \text { with } S=\left(X^{T} X\right)^{-1} X^{T}
$$

This least squares estimator makes it possible to develop the approximation model, shown in Figure 13 , with good quality estimates of the reliability variables affected by random errors, with estimation of $\hat{a}=0.01551676, \hat{b}=0.901499$ and $\hat{\lambda}=$ -0.0004526382 .

The synthesis of the different reliability analyzes for the goodness of fit of gas turbine failure prediction examined, using the two-parameter Weibull model and the modified Weibull model with the different estimators used are shown in Tables 4 and 5. Where Table 3 shows the results obtained with reliability modeling errors and Table 4 presents the results obtained from the estimated reliability parameters of gas turbine MS5002C.

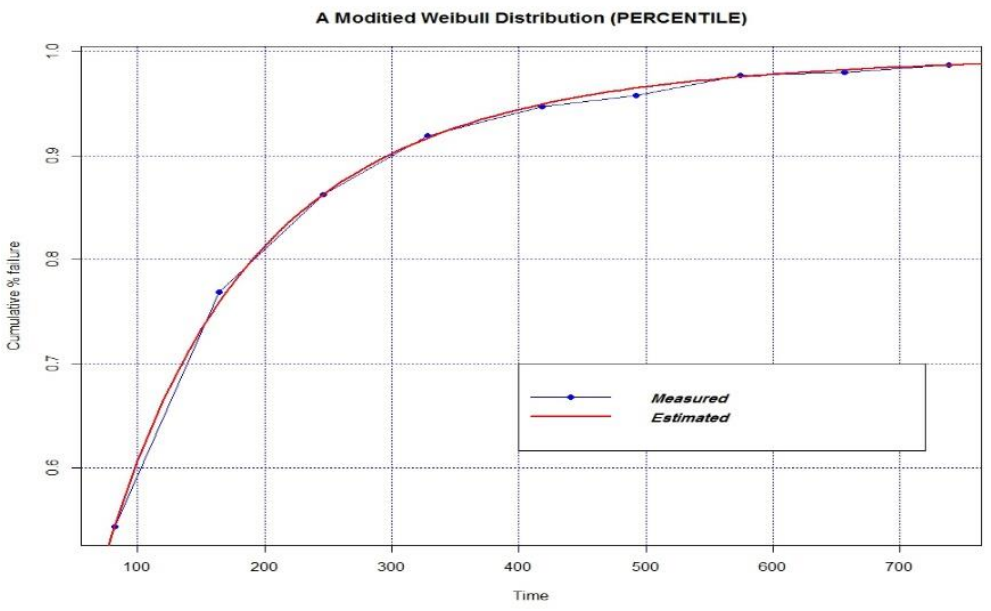

Fig. 11. Evolution of modified Weibull-based turbine failures with estimator of the non-parametric regression method of the percentiles

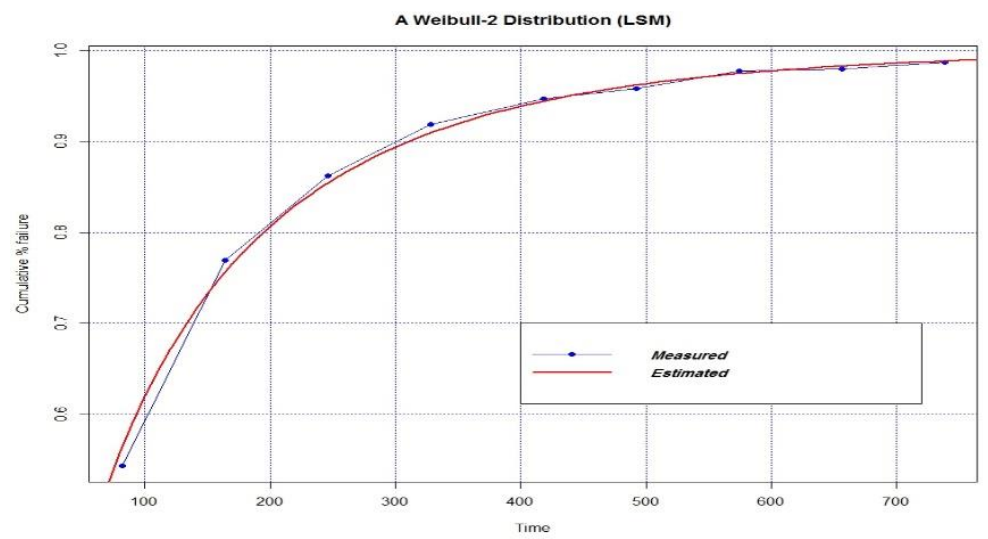

Fig. 12. Evolution of two-parameter Weibull-based turbine failures with least squares estimator

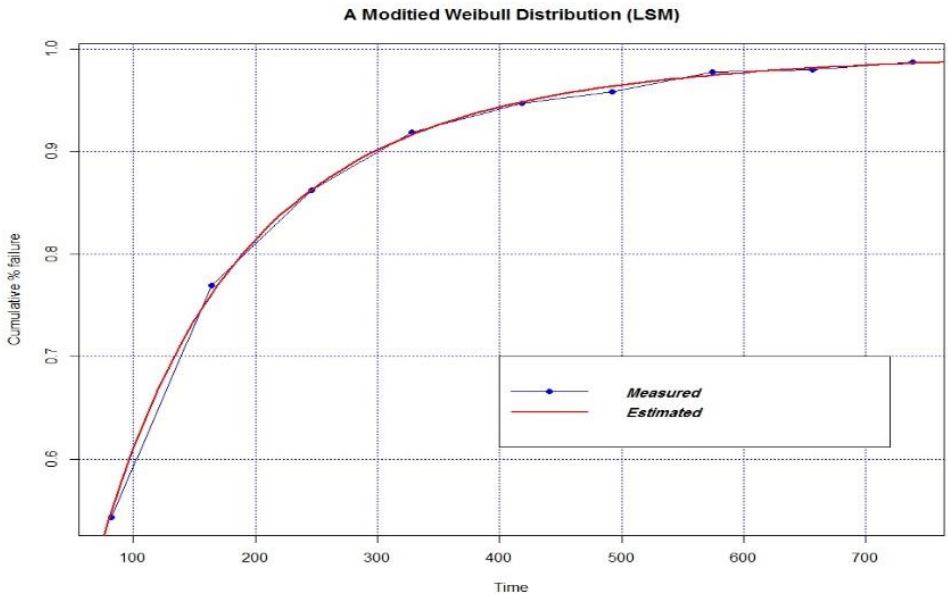

Fig. 13. Evolution of modified Weibull-based turbine failures with least squares estimator 
Table 3. Obtained results of MS5002C gas turbine reliability modeling errors

\begin{tabular}{cllll}
\hline & $\begin{array}{c}\text { Mean Squared } \\
\text { Error } \\
\text { Two-parameter } \\
\text { Weibull }\end{array}$ & $\begin{array}{c}\text { Mean Squared } \\
\text { Error } \\
\text { Modified } \\
\text { Weibull }\end{array}$ & $\begin{array}{c}\text { Root Mean Square } \\
\text { Error } \\
\text { Two-parameter } \\
\text { Weibull }\end{array}$ & $\begin{array}{c}\text { Root Mean Square } \\
\text { Error } \\
\text { Modified Weibull }\end{array}$ \\
\hline $\begin{array}{c}\text { Maximum Likelihood } \\
\text { Estimator (MLE) }\end{array}$ & $6.400752 \mathrm{e}-06$ & $7.046527 \mathrm{e}-09$ & 0.002529971 & $8.394359 \mathrm{e}-05$ \\
\hline $\begin{array}{c}\text { Moments Method Estimator } \\
\text { (MME) }\end{array}$ & $6.820 \mathrm{e}-05$ & - & 0.008258534 & - \\
\hline Percentiles Regression & 0.0005399404 & $2.414 \mathrm{e}-07$ & 0.02323662 & 0.000491399 \\
\hline $\begin{array}{c}\text { Least Squares Estimator } \\
\text { (LSE) }\end{array}$ & $5.067 \mathrm{e}-06$ & $2.402 \mathrm{e}-07$ & 0.002251026 & 0.0004901594 \\
\hline
\end{tabular}

Table 4. Obtained results from estimated reliability parameters of MS5002C gas turbine

\begin{tabular}{|c|c|c|c|c|c|}
\hline & \multicolumn{2}{|c|}{ Two-parameter Weibull } & \multicolumn{3}{|c|}{ Modified Weibull } \\
\hline & $\beta$ & $\lambda$ & $\mathrm{a}$ & $\mathrm{b}$ & $\lambda$ \\
\hline $\begin{array}{l}\text { Maximum Likelihood } \\
\text { Estimator (MLE) }\end{array}$ & 0.8694809 & 107.6626769 & 0.0254027 & 0.7754443 & 0.000397175 \\
\hline $\begin{array}{l}\text { Moments Method Estimator } \\
\text { (MME) }\end{array}$ & 0.9625049 & 120.1602 & - & - & - \\
\hline Percentiles Regression & 0.7809538 & 100.0366 & 0.01467593 & 0.9107816 & -0.0004348491 \\
\hline Least Squares Estimator (LSE) & 0.7666161 & 104.6549 & 0.01551676 & 0.901499 & -0.0004526382 \\
\hline
\end{tabular}

After the operation of the turbine reliability data examined, with estimation of the turbine operating data, based on the two-parameter Weibull model and the proposed modified Weibull distribution model, from recorded failure data on this machine, which increases over time. For the purpose of developing a decision support strategy for the maintenance of this turbine, to increase their operating profitability.

\section{MAINTENANCE OF MS5002C GAS TURBINE BASED ON THEIR RELIABILITY RATINGS}

The operation of a gas turbine, must include a planned program of periodic inspections and, if necessary, the replacement of defective parts, in order to ensure maximum utilization and reliability of the turbine. Indeed, in the case of the MS5002C gas turbine, after the various reliability calculations of this machine, inspections can be programmed on the combustion system after 12,000 working hours and 800 starting sequences, the hot part 24,000 hours of operation. work and 1,200 starting sequences with a general overhaul for 48,000 working hours and 2,400 starting sequences. Operating data must be acquired in all transient phases (start, stop) and in steady state condition during normal machine operation. This operation is used to have reference values on consumption, performance, for proper programming of maintenance actions. This will allow a better assessment of any change in the operation of the gas turbine during its life and will help to discover the causes of possible faults and to choose the appropriate solutions.

For this, the three turbine parts; Combustion system, hot gas stream and turbine section have been inspected, as shown in Table 5. For the inspection of the combustion system, to check the condition of the burner elements, the combustion chamber (jacket, bonnet, outlet socket), interconnecting tubes, spark plugs and flame detectors. The purpose of the inspection of the hot gas exhaust part is to examine the parts of the turbine that are most subjected to stress by the high temperatures of the combustion gas system, this inspection essentially includes the guidelines of all the turbine stages, the rotor blades and the outer protection rings. And the general overhaul of the turbine aims to inspect and examine all interior parts of the rotor and stator, from the inlet of the filter chamber to the exhaust system, including the load reducer. and the driven machine.

The development of a schedule for inspections of the MS5002C gas turbine is for the purpose of making a maintenance plan, which will reduce the downtime and increase the uptime of this turbine. For the combustion system, Figure 14 shows the inspection of the flame tubes made during the maintenance process and Figure 15 shows the inspection of the injector tanks, according to the signs of failure obtained. As well as a general overhaul is made on the gas turbine MS5002C, for the compressor section and the turbine section, as shown in Figure 16 up to Figure 19, according to the different turbine technical specifications and reliability indices. obtained. Figure 16 shows a general overhaul of a high pressure HP turbine, Figure 17 shows a general overhaul of the rotor, Figure 18 shows a general overhaul of the compressor and Figure 19 shows a general overhaul of the turbine section to observe the different rotor and stator parts of the machine. 
Table 5. Maintenance inspections of the MS5002C gas turbine

\begin{tabular}{|c|c|c|c|}
\hline Section & Element & Object of the inspection & Potential actions \\
\hline 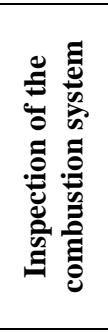 & $\begin{array}{l}\text { Combustion jacket } \\
\text { Combustion cap } \\
\text { Burner } \\
\text { Transition piece } \\
\text { Interconnection tubes } \\
\text { Purge valve } \\
\text { Check valves } \\
\text { Spark plugs } \\
\text { Flame detectors } \\
\end{array}$ & & $\begin{array}{l}\text { Repair / overhaul: } \\
\text { Combustion chambers } \\
\text { Transition piece } \\
\text { Burners } \\
\text { Interconnection tubes }\end{array}$ \\
\hline 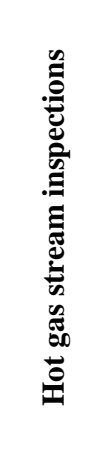 & $\begin{array}{l}\text { Directors, all floors } \\
\text { Blades, all floors } \\
\text { Outer protection ring } \\
\text { Labyrinth seals } \\
\text { Wheel space thermocouple } \\
\text { Turbine exhaust housing } \\
\text { Axial compressor discharge } \\
\text { vanes } \\
\text { IGV }\end{array}$ & $\begin{array}{l}\text { Foreign bodies } \\
\text { Distortions and deformations } \\
\text { Coating condition } \\
\text { Cracks } \\
\text { Games } \\
\text { Clogged cooling holes } \\
\text { Oxidation / Corrosion / Erosion } \\
\text { Loss of small interior particles } \\
\text { Traces of internal leakage } \\
\text { Traces of local excessive temperature } \\
\text { Clogged cooling holes } \\
\text { Abnormal wear }\end{array}$ & $\begin{array}{l}\text { Repair / overhaul } \\
\text { Directors } \\
\text { Restitution coating } \\
\text { Blades }\end{array}$ \\
\hline 总 & $\begin{array}{l}\text { Compressor vanes } \\
\text { Turbine wheels } \\
\text { Blade dovetails } \\
\text { Supported area of the tree } \\
\text { Bearings } \\
\text { Labyrinth seals } \\
\text { Intake system } \\
\text { Exhaust system } \\
\text { Other auxiliary systems }\end{array}$ & & $\begin{array}{l}\text { Repair / Repair } \\
\text { Directional blades } \\
\text { Stator protection rings } \\
\text { IGV } \\
\text { Bearings and seals } \\
\text { Compressor vanes }\end{array}$ \\
\hline
\end{tabular}

However, implementing this maintenance process is done after an analysis of the various operating factors influencing the maintenance of the turbine. Hence, the factors having the most influence on the life of the parts are the frequency of starts and the load on this rotating machine. Hence, at each turbine startup, the parts of the hot gas path are subjected to a considerable thermal cycle.

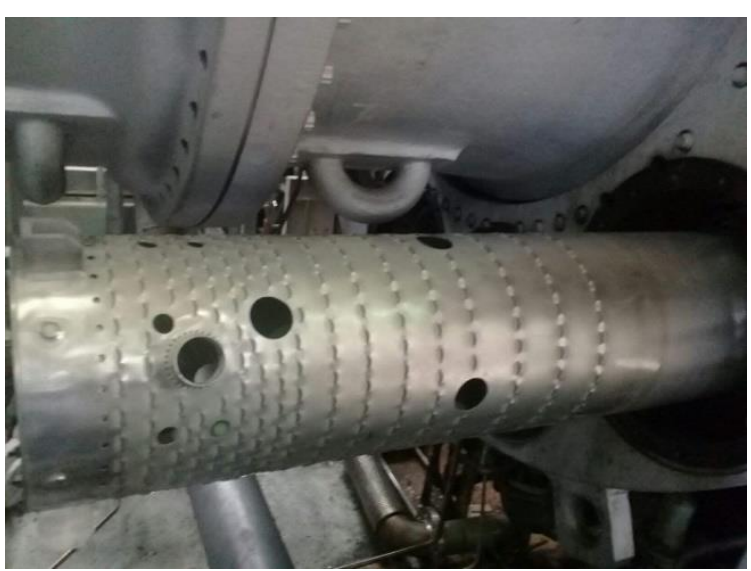

Fig. 14. Inspection of the flame tubes
Practically, when the starts and stops of a turbine are frequent, the life of the parts of the gas-path heat is shorter than that of parts of another turbine operating in service. As well as the variation of the turbine load, up to $100 \%$ of the power, moderately influences the life of the turbine parts, in particular, if this variation is frequently abrupt.

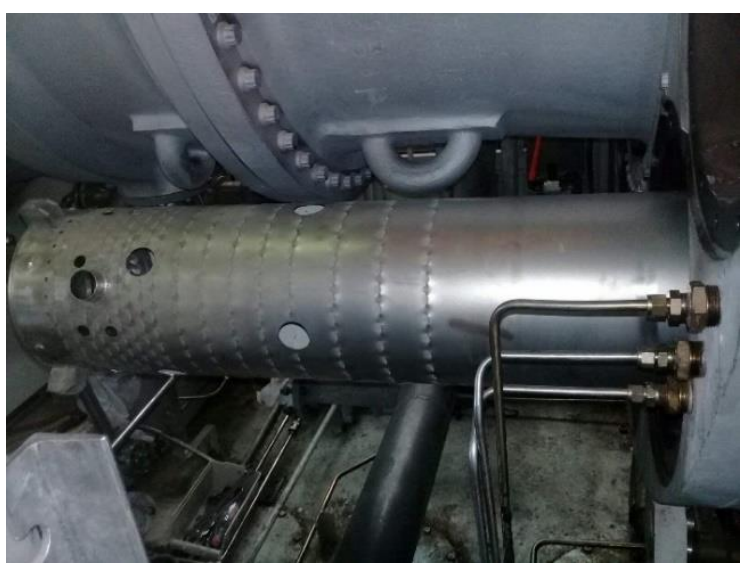

Fig. 15. Inspection of injector tanks 


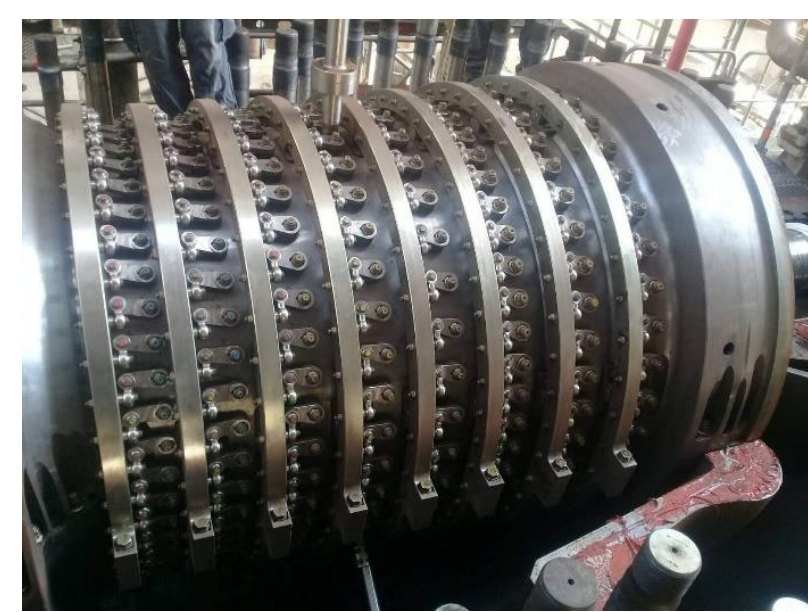

Fig. 16. General high pressure turbine overhaul

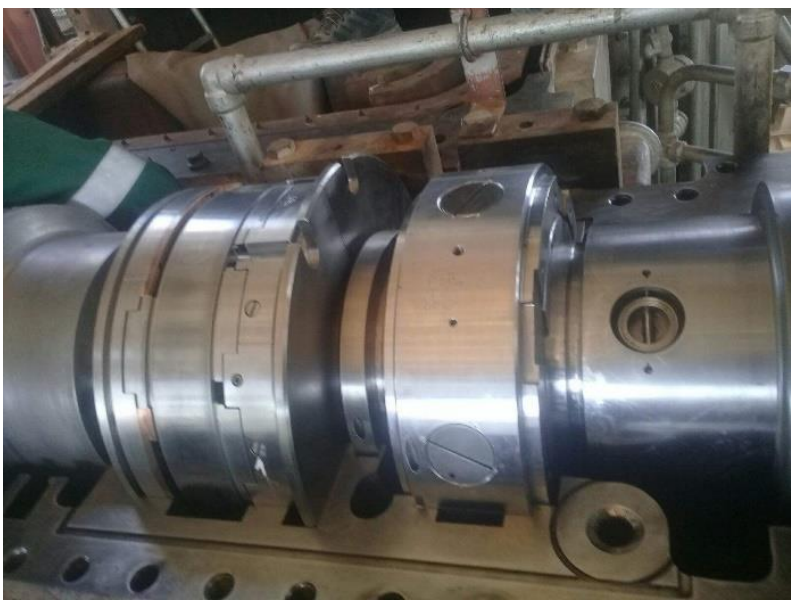

Fig. 17. General rotor overhaul

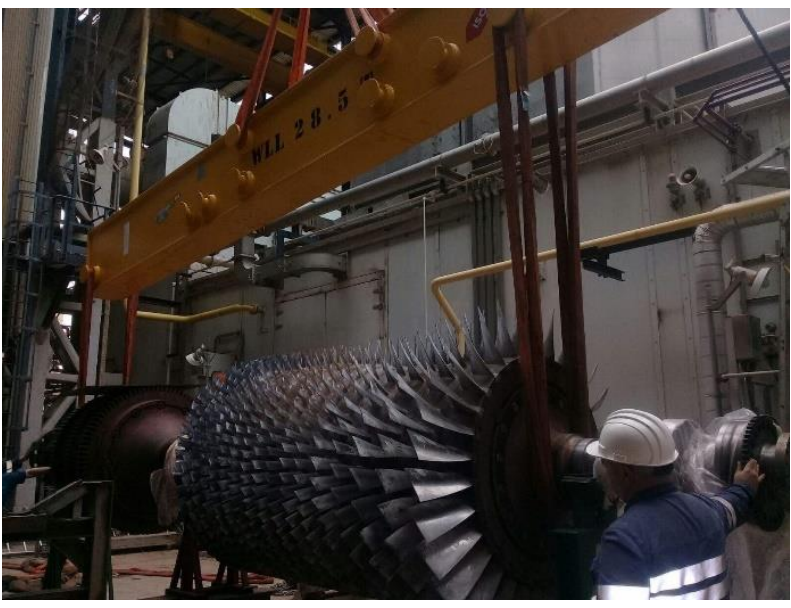

Fig. 18. General compressor overhaul

Correct operation of the MS5002C gas turbine depends on the developed maintenance program. The aim is to keep equipment in good operating conditions, detect problems and breakdowns, and diagnose the nature and severity of failures that occur during their operation. Based on an analysis and identification of all failure modes, using reliability indices which are expressed by welladapted models to get stable operation with good reliability.

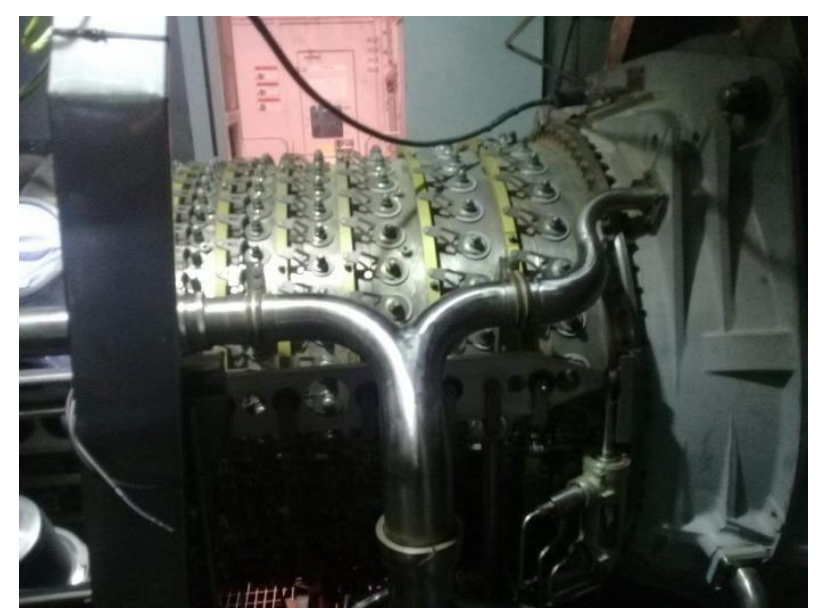

Fig. 19. General turbine section overhaul

\section{CONCLUSION}

The proposed two-parameter Weibull and modified Weibull MS5002C gas turbine reliability models have been tested and validated, with prediction errors converging to zero. This approach made it possible to model the acts of degradation of the components of the examined gas turbine, and to estimate and plan the duration of malfunction for a scheduled maintenance of this machine. First, the graphical method which uses a functional scale paper of the Weibull paper is made to obtain the parameters of the reliability model. Then, the turbine reliability estimation is modeled using turbine operating data based on two reliability models. The first model is the two-parameter Weibull model, and the second proposed model is based on the derivative of the modified Weibull distribution. After the statistical study of the investigated turbine failures, using four methods to determine their estimated parameters from these two reliability models. A comparative study was developed to determine the best estimate of these parameters. In this perspective, this work confirms that the method with maximum likelihood estimator gives best estimates with small mean squared errors using the modified Weibull distribution for the case of the studied turbine.

The obtained results in this work show that the reliability models of the gas examined turbine using the two-parameter Weibull distribution allows to estimates $\hat{\beta}=0.8694809$ and $\hat{\lambda}=107.6626769$, the use of the proposed modified Weibull distribution gives estimated values $\hat{a}=0.0254027$, $\hat{b}=0.7754443$ and $\hat{\lambda}=0.000397175$ with perfect fit with estimation based on maximum likelihood. For the case of estimation based on the moments method, the two-parameter Weibull distribution gives an estimate of $\hat{\beta}=0.9625049$ and $\hat{\lambda}=$ 120.1602 , but for the modified Weibull distribution, it is not possible to use the moments method to estimate the parameters of the distribution, because the expressions of moments are analytically insolvent. Also, the estimation based on the nonparametric regression method of the percentiles, 
the obtained results by two-parameter Weibull allows to estimate $\hat{\lambda}=100.0366$ for the probabilities $P_{1}=0.5433168$ and $P_{2}=$ 0.9872112 and for the estimated value $\hat{\beta}=$ 0.7809538 for the probabilities $P_{1}=0.8626238$ and $P_{2}=0.9773102$.

Hence, the proposed modified Weibull distribution allows the selection of the probabilities, $P_{1}, P_{2}$ and $P_{3}$ of the percentiles of the minimized sample of the studied turbine failure data, this allows to estimate $\hat{a}=0.01467593, \hat{b}=0.9107816$ and $\hat{\lambda}=-0.0004348491$, for the probabilities $P_{1}=$ 0.5433168, $P_{2}=0.9872112$ and $P_{3}=$ 0.8626238 . And finally, the study of estimation based on the least squares method makes it possible to develop the approximation model based on Weibull with two parameters, with the estimates of the variables of $\hat{a}=104.6549$ and $\hat{b}=0.7666161$ and allows to develop the model of approximation for the proposed modified Weibull distribution, with good quality estimates of the reliability variables affected by random errors, with estimation of $\hat{a}=$ $0.01551676, \quad \hat{b}=0.901499$ and $\hat{\lambda}=$ -0.0004526382 .

This makes it possible to develop the examined turbine maintenance plan base on the obtained results from analysis of reliability indices using actual data of turbine failure times with modified Weibull model exploration. This study and analysis then made it possible to improve their operation with a good analysis of the experience feedback, and to provide essential data to establish the maintenance choices for the development of the reliability method with experience feedback.

Author contributions: research concept and design, D.A.Z.; Collection and/or assembly of data, D.A.Z.; Data analysis and interpretation, D.A.Z., I.A.; Writing the article, D.A.Z., I.A., K.A.; Critical revision of the article, A.H.; Final approval of the article, A.H.

Declaration of competing interest: The authors declare that they have no known competing financial interests or personal relationships that could have appeared to influence the work reported in this paper.

\section{REFERENCES}

1. Alblawi A. Fault diagnosis of an industrial gas turbine based on the thermodynamic model coupled with a multi feedforward artificial neural networks. Energy Reports, 2020;6:1083-1096. https://doi.org/10.1016/j.egyr.2020.04.029.

2. Djeddi AZ, Hafaifa A, Salam A. Operational reliability analysis applied to a gas turbine based on three parameter Weibull distribution. Mechanics, 2015; 21(3):187-192. https://doi.org/10.5755/j01.mech.21.3.12539

3. Djeddi AZ, Hafaifa A, Kouzou A, Abudura S. Exploration of reliability algorithms using modified Weibull distribution: Application on gas turbine. International Journal of System Assurance
Engineering and Management, 2017;8:1885-1894. https://doi.org/10.1007/s13198-016-0480-9

4. Djeddi AZ, Hafaifa A, Salam A. Gas turbine reliability model based on tangent hyperbolic reliability function. Journal of Theoretical and Applied Mechanics, 2015; 53(3):723-730. https://doi.org/10.15632/jtampl.53.3.723

5. Jeddi AZ, Hafaifa A, Guemana M, Kouzou A. Gas turbine reliability modelling based on a bath shaped rate failure function: modified Weibull distribution validation. Life Cycle Reliability and Safety Engineering, 2020;9:437-448.

https://doi.org/10.1007/s41872-020-00149-6.

6. Barak MS, Reena G, Ajay K. Reliability measures analysis of a milk plant using RPGT. Life Cycle Reliability and Safety Engineering, 2021; 10: 295-302. https://doi.org/10.1007/s41872-020-00163-8.

7. Mohamed BR, Hafaifa A, Kouzou A, XiaoQi C. Monitoring of high-speed shaft of gas turbine using artificial neural networks: predictive model application. Diagnostyka, 2017; 18(4):3-10.

8. Saadat B, Kouzou A, Guemana M, Hafaifa A. Availability phase estimation in gas turbine based on prognostic system modeling. Diagnostyka, 2017;18(2):3-11.

9. Djeddi C, Hafaifa A, Iratni A, Hadroug N, Chen XQ. Robust diagnosis with high protection to gas turbine failures identification based on a fuzzy neuro inference monitoring approach. Journal of Manufacturing Systems, 2021;59:190-213.

https://doi.org/10.1016/j.jmsy.2021.02.012.

10. Zhou D, Huang D, Hao J, Wu H, Chang C, Zhang H. Fault diagnosis of gas turbines with thermodynamic analysis restraining the interference of boundary conditions based on STN. International Journal of Mechanical Sciences, 2021; 191:106053. https://doi.org/10.1016/j.ijmecsci.2020.106053.

11. Zhou D, Yao Q, Wu H, Ma S, Zhang H. Fault diagnosis of gas turbine based on partly interpretable convolutional neural networks. Energy, 2020;200: 117467. https://doi.org/10.1016/j.energy.2020.117467

12. Halimi D, Hafaifa A, Bouali E. Maintenance actions planning in industrial centrifugal compressor based on failure analysis. The Quarterly Journal of Maintenance and Reliability, 2014;16(1):17-21.

13. Han D, Tian J, Xue P, Shi P. A novel intelligent fault diagnosis method based on dual convolutional neural network with multi-level information fusion. Journal of Mechanical Science and Technology, 2021; 35:3331-3345. https://doi.org/10.1007/s12206-0210707-9.

14. Ramos E, Ramos PL, Louzada F. Posterior properties of the Weibull distribution for censored data. Statistics \& Probability Letters, 2020; 166:108873. https://doi.org/10.1016/j.spl.2020.108873

15. Herman Shen MH. Reliability assessment of high cycle fatigue design of gas turbine blades using the probabilistic Goodman Diagram. International Journal of Fatigue, 1999;21(7):699-708. https://doi.org/10.1016/S0142-1123(99)00033-X.

16. Zhao J, Oh U, Lee Y, Park J, Choi J. A study on reliability and capacity credit evaluation of China power system considering WTG with multi energy storage systems. Journal of Electrical Engineering \& Technology, 2021;16:2367-2378. https://doi.org/10.1007/s42835-021-00775-9.

17. Błachnio J, Spychała J, Zasada D. Analysis of structural changes in a gas turbine blade as a result of 
high temperature and stress. Engineering Failure Analysis, 2021;127:105554.

https://doi.org/10.1016/j.engfailanal.2021.105554.

18. Song KL, Bai GC, Li XQ, Wen J. A unified fatigue reliability-based design optimization framework for aircraft turbine disk. International Journal of Fatigue, 2021;152:106422.

https://doi.org/10.1016/j.ijfatigue.2021.106422

19. Verma M, Kumar A. A novel general approach to evaluating the reliability of gas turbine system. Engineering Applications of Artificial Intelligence, 2014;28:13-21.

https://doi.org/10.1016/j.engappai.2013.10.001

20. Bai M, Yang X, Liu J, Liu J, Yu D. Convolutional neural network-based deep transfer learning for fault detection of gas turbine combustion chambers. Applied Energy, 2021;302: 117509. https://doi.org/10.1016/j.apenergy.2021.117509.

21. Ali MA, Barakat MM, Abokhalaf MM, Fadel YH, Kandil M, Rasmy MW, Ali ON, Besheer AH, Emara HM, Bahgat A. Micro-grid monitoring and supervision: Web-based SCADA approach. Journal of Electrical Engineering \& Technology, 2021;16:23132331. https://doi.org/10.1007/s42835-021-00762-0.

22. Rahmoune MB, Hafaifa A, Kouzou A, Chen XQ, Chaibet A. Gas turbine monitoring using neural network dynamic nonlinear autoregressive with external exogenous input modelling. Mathematics and Computers in Simulation, 2021;179:23-47. https://doi.org/10.1016/j.matcom.2020.07.017

23. Gh MM, Yazdani S. Application of interval type- 2 fuzzy logic systems to gas turbine fault diagnosis. Applied Soft Computing, 2020;96:106703. https://doi.org/10.1016/j.asoc.2020.106703.

24. Gh MM, Nekoonam A, Yazdani S. A novel approach to gas turbine fault diagnosis based on learning of fault characteristic maps using hybrid residual compensation extreme learning machine-growing neural gas model. Journal of the Brazilian Society of Mechanical Sciences and Engineering, 2021;43(9):115. https://doi.org/10.1007/s40430-021-03136-9.

25. Guemana M, Hafaifa A Rahmoune MB. Reliability study of gas turbines for improving their availability by ensuring optimal exploitation. OIL GAS European Magazine, 2015;2:88-91.

26. Hadroug N, Hafaifa A, Iratni A, Guemana M. Reliability modeling using an adaptive neuro-fuzzy inference system: Gas turbine application. Fuzzy Information and Engineering, 2021. https://doi.org/10.1080/16168658.2021.1915451.

27. Hadroug N, Hafaifa A, Kouzou A, Chaibet A. Improvement of gas turbine availability using reliability modeling based on fuzzy system. Chapter in Applied Condition Monitoring book series, ICDT 2016: Advances in Technical Diagnostics, 2018;10: 15-28. https://doi.org/10.1007/978-3-319-62042-8_2.

28. Wong PK, Yang Z, Vong CN, Zhong J. Real-time fault diagnosis for gas turbine generator systems using extreme learning machine. Neurocomputing, 2014; 128:249-257. https://doi.org/10.1016/j.neucom.2013.03.059.

29. Balducci P, Mongird K, Weimar M. Understanding the value of energy storage for power system reliability and resilience applications. Current Sustainable and Renewable Energy Reports, 2021;8: 131-137. https://doi.org/10.1007/s40518-021-00183-7.

30. Strzelecki P. Determination of fatigue life for low probability of failure for different stress levels using 3- parameter Weibull distribution. International Journal of Fatigue, 2021;145:106080.

https://doi.org/10.1016/j.ijfatigue.2020.106080.

31. Tryon RG, Cruse TA, Mahadevan S. Development of a reliability-based fatigue life model for gas turbine engine structures. Engineering Fracture Mechanics, 1996; 53(5): 807-828. https://doi.org/10.1016/00137944(95)00138-7.

32. Sun R, Shi L, Yang X, -Wang Y, Zhao Q. A coupling diagnosis method of sensors faults in gas turbine control system. Energy, 2020;205:117999. https://doi.org/10.1016/j.energy.2020.117999

33. Amirkhani S, Chaibakhsh A, Ghaffari A. Nonlinear robust fault diagnosis of power plant gas turbine using Monte Carlo-based adaptive threshold approach. ISA Transactions, 2020;100:171-184. https://doi.org/10.1016/j.isatra.2019.11.035

34. Rahme S, Meskin N. Adaptive sliding mode observer for sensor fault diagnosis of an industrial gas turbine. Control Engineering Practice, 2015;38: 57-74. https://doi.org/10.1016/j.conengprac.2015.01.006.

35. Park S, Shin J, Morishita M, Saitoh T, Choi G, Tanahashi M. Validation of measured data on F/A ratio and turbine inlet temperature with optimal estimation to enhance the reliability on a full-scale gas turbine combustion test for IGCC. International Journal of Hydrogen Energy, 2019;44(26):1399914011. https://doi.org/10.1016/j.ijhydene.2019.03.233

36. Yazdani S, Skates MH, Holden G. Adding more by using less: Adaptive reuse of woolstores. Procedia Engineering, 2017;180:697-703. https://doi.org/10.1016/j.proeng.2017.04.229.

37. Yazdani S, Gh MM. A novel gas turbine fault detection and identification strategy based on hybrid dimensionality reduction and uncertain rule-based fuzzy logic. Computers in Industry, 2020;115:103131. https://doi.org/10.1016/j.compind.2019.103131.

38. Zhong SS, Fu S, Lin L. A novel gas turbine fault diagnosis method based on transfer learning with CNN. Measurement, 2019;137:435-453. https://doi.org/10.1016/j.measurement.2019.01.022.

39. Aissat S, Hafaifa A, Iratni A, Guemana M. Identification of two-shaft gas turbine variables using a decoupled multi-model approach with genetic algorithm. Periodica Polytechnica Mechanical Engineering, 2021; 65(3): 229-245. https://doi.org/10.3311/PPme.17206.

40. Simani S, Fantuzzi C. Dynamic system identification and model-based fault diagnosis of an industrial gas turbine prototype. Mechatronics, 2006;16(6):341-363. https://doi.org/10.1016/j.mechatronics.2006.01.002.

41. Olsson T, Ramentol E, Rahman M, Oostveen M, Kyprianidis K. A data-driven approach for predicting long-term degradation of a fleet of micro gas turbines. Energy and AI, 2021; 4:100064. https://doi.org/10.1016/j.egyai.2021.100064.

42. Xiao YQ, Liu ZY, Zhu W, Peng XM. Reliability assessment and lifetime prediction of TBCs on gas turbine blades considering thermal mismatch and interfacial oxidation. Surface and Coatings Technology, 2021;423:127572. https://doi.org/10.1016/j.surfcoat.2021.127572

43. Li XQ, Bai GC, Song LK, Wen J. Fatigue reliability estimation framework for turbine rotor using multiagent collaborative modeling. Structures, 2021;29: 1967-1978.

https://doi.org/10.1016/j.istruc.2020.12.068. 
44. Yang X, Bai M, Liu J, Liu J, Yu D. Gas path fault diagnosis for gas turbine group based on deep transfer learning. Measurement, 2021;181:109631. https://doi.org/10.1016/j.measurement.2021.109631.

45. Shen Y, Khorasani K. Hybrid multi-mode machine learning-based fault diagnosis strategies with application to aircraft gas turbine engines. Neural Networks, 2020;130:126-142. https://doi.org/10.1016/j.neunet.2020.07.001.

46. Chen YZ, Zhao XD, Xiang HC, Tsoutsanis E. A sequential model-based approach for gas turbine performance diagnostics. Energy, 2021; 220:119657. https://doi.org/10.1016/j.energy.2020.119657

47. Liao Z, Wang J, Liu J, Geng J, Li M, Chen X, Song Z. Uncertainties in gas-path diagnosis of gas turbines: Representation and impact analysis. Aerospace Science and Technology, 2021;113:106724. https://doi.org/10.1016/j.ast.2021.106724

48. Liu ZH, Meng XD, Wei HL, Chen L, Lu BL, Wang $\mathrm{ZH}$, Chen L. A regularized LSTM method for predicting remaining useful life of rolling bearings. International Journal of Automation and Computing, 2021;18:581-593. https://doi.org/10.1007/s11633020-1276-6.

\section{Received 2021-08-29}

Accepted 2022-01-99

Available online 2022-02-09

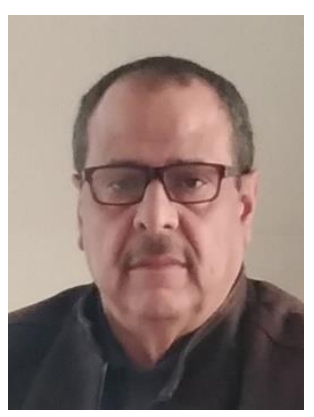

Dr Ahmed Zohair Djeddi, was born in Medea on 1966, he obtained his state engineering degree in Electronics and the Magister degree from the University of Blida on 1999 and 2004 respectively. In May 2016 he obtained the Doctor degree in Engineering process from the University of MEDEA. His main researches are on reliability and availability approaches in industrial system for development tools and sustainability issues, competitiveness, safety and security of complex industrial systems. His research are mainly focussing on applications of equipment and rotating machinery in oil and gas transportation industry, in order to increase the effectiveness of these petroleum installations, to increase the prevention against failures of the gas turbines based on reliabilities approaches, to ensure maximum uptime and optimize decision-making and implementation of maintenance policies of these machines. He has supervised several graduate students and written many conferences and journal papers.

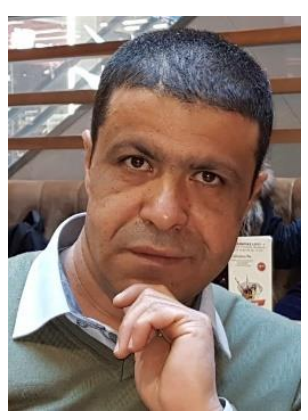

Prof. Ahmed HAFAIFA was born in Algeria in 1974, He is a $\mathrm{PhD}$ and Full Professor in Industrial Process: Automation / Diagnosis and Reliability Engineering at the Science and Technology Faculty of the University of Djelfa, Algeria, where $\mathrm{He}$ is actually the Dean of the Science and Technology Faculty since April 2018, after serving as the leader of Science and Technology Filed for five years since October 2014. Currently $\mathrm{He}$ is the Director of the Applied Automation and Industrial Diagnostic Laboratory of the University of Djelfa and the leader of the Gas Turbine Joint Research Team, where Hi is the founder of these research entities, where Hi is initiated and supported several international research projects in collaboration and innovation activities with the industrial sector.

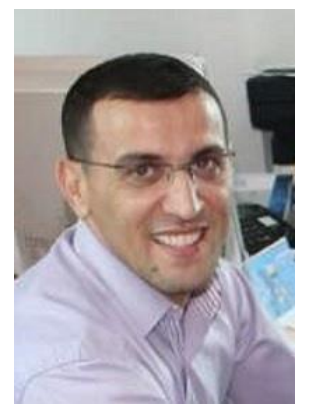

Dr Abdelhamid IRATNI is an associate Professor control engineering and automation systems at the Electrical Engineering department of faculty of Science and Technology at University of Bordj Bou Arreridj, Algeria, where he has been a faculty member since 2004. He is the Chair of the scientific committee of the Electrical Engineering department since 2019 after serving as the head of Automatic control bachelor and master programs for 3 years since 2015. Dr Abdelhamid IRATNI received his BSc and MSc degrees in electrical engineering from the University of Boumerdes, Algeria, in 1999 and 2003, respectively. He received his $\mathrm{PhD}$ from the University of Setif, Algeria, in 2013. His current research areas include nonlinear filtering, estimation and control, biomedical and bioprocess engineering, and automation and reliability of industrial systems.

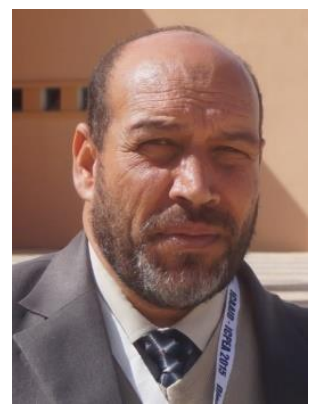

Prof. Abdellah KOUZOU (IEEE Senior member \& IACSIT Senior member, IFAC, IAENG \& IISRO member, IEEE-HKN Alumni Member) was born in Djelfa, Algeria in 1964. He is a collaborator researcher at Texas A\&M University at Qatar. He has been the president of the Scientific council of the faculty since June 2014. He has participated in several research projects and has led several research projects. He is the founder of the Power Electronics and Power Quality research group at the Applied Automation and Industrial Diagnostic Laboratory, University of Djelfa in Algeria. He is the supervisor of many $\mathrm{PhD}$ Students in Algeria. $\mathrm{He}$ is a member of the Smart Grid Center at Qatar SGC-Q. He is a member of many editorial boards for several scientific journals and a member of the scientific and steering committees in several national and international conferences. 